Distribution Category:

Energy Conservation--

Industry (UC-95f)

ANL- $-87-28$

ANL $-87-28$

DE88 001955

\begin{abstract}
ARGONNE NATIONAL LABORATORY
9700 South Cass Avenue

Argonne, Illinots 60439
\end{abstract}

A REVIEW OF TWO-PHASE FLOW-INDUCED VIBRATION

by

S. S. Chen

Materials and Components Technology Division

August 1987 


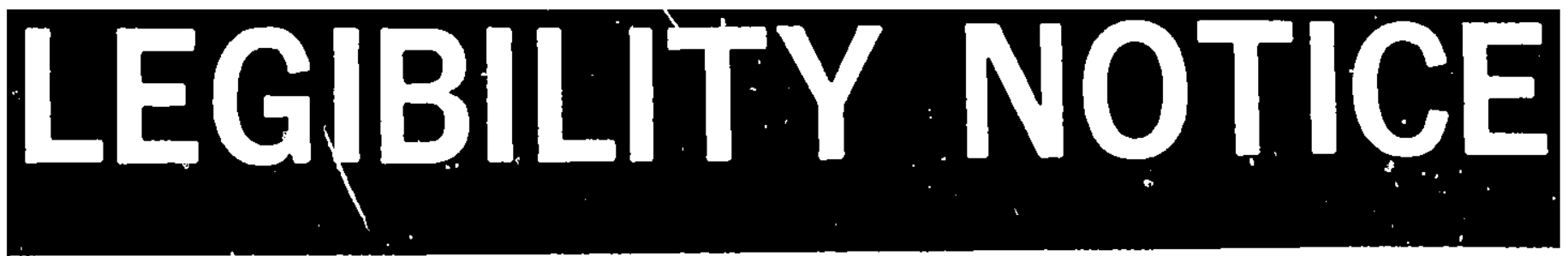

A major purpose of the Technical Information Center is to provide the broadest dissemination possible of information contained in DOE's Research and Development Reports to business, industry, the academic community, and federal, state and iocal governments.

Although a small portion of this report is not reproducible, it is being made available to expedite the availability of information on the research discussed herein. 


\section{CONTENTS}

Page

ABSTRACT. ..........................................

I. InTRODUCTION. $\ldots \ldots \ldots \ldots \ldots \ldots \ldots \ldots \ldots \ldots \ldots \ldots \ldots \ldots \ldots \ldots \ldots \ldots \ldots \ldots \ldots$

II. ADDED MASS AND DAMPING........................... 4

III. CROSSFLOW-IMDUCEd VIbRATION........................ 11

IV. AXIAL-FLOW-INDUCED VIBRATION $\ldots \ldots \ldots \ldots \ldots \ldots \ldots \ldots \ldots \ldots \ldots \ldots \ldots \ldots \ldots \ldots \ldots$

v. CLOSING REMARKS................................. 38

ACKNOWLEDGMENTS........................................ 39

REFERENCES.......................................... 40 


\section{PIGURES}

Page

1 Effective density for two-phase flow as a function of vold fraction...................................... 5

2 Two-phase flow damping coefficient....................

3 A group of circular cylinders in fluid................... 9

4 Wake behind a cylinder: (a) water flow ( $U=0.4 \mathrm{~m} / \mathrm{s})$,

(b) osclllatory wake in two-phase flow ( $U=0.4 \mathrm{~m} / \mathrm{s}, \alpha=0.06$ ),

(c) steady wake in two-phase flow $(U=0.4 \mathrm{~m} / \mathrm{s}, \alpha=0.2) \ldots \ldots \ldots .16$

5 Time historles of $11 \mathrm{ft}$ and drag forces for $\alpha=70 \% \ldots \ldots \ldots \ldots \ldots$

6 RMS values of $11 \mathrm{ft}$ and drag forces as a function of gap velocity and vold fraction.................................. 18

7 The rms accelerations of a cylinder as a function of reduced flow velocity U/fD: (a) in-line direction; (b) crossflow direction......................................... 21

8 Vibration characteristics............................ 23

$9 \quad$ Stability map.................................... 25

10 Flow patterns in axial flow as a function of void fraction ...... 33

11 Typical longitudinal spatial correlation of fluid pressure...... 34

12 Typical peripheral spatial correlation of fluid pressure ...... 35

13 Vartance of vibration strain and two-phase flow Reynolds

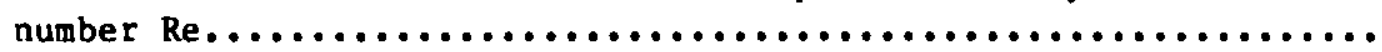




\section{TABLES}

$\underline{\text { Page }}$

1 Tests on two-phase crossflow-induced vibration.............. 


\section{NOMENCLATURE}

Symbol

A

$\mathrm{C}_{\mathrm{Dj}}\left(\mathrm{C}_{\mathrm{Lj}}\right)$

$C_{D_{j}}^{\prime}\left(C_{L j}^{\prime}\right)$

$\mathrm{c}_{\mathrm{m}}$

$\mathrm{C}_{\mathrm{N}}, \mathrm{C}_{\mathrm{T}}$

$\mathrm{C}_{\mathrm{s}}, \mathrm{C}_{\mathrm{sj}}$

$\mathrm{c}_{\mathrm{t}}$

$\mathrm{C}_{\mathrm{v}}$

D

$E_{j} I_{j}, E I$

f

$\mathrm{f}_{\mathrm{f}}$

fv

g

$\mathrm{g}_{\mathbf{j}}$

$g_{j}^{\prime}$

$\mathrm{h}_{\mathrm{j}}$

$h_{j}$

$\ell$

m

$\mathrm{m}_{\mathrm{a}}$

$\mathrm{m}_{\mathrm{j}}$

$M_{d}$

N

P

Q

Re

t

T

u

$\mathbf{u}_{j}$

Description

Channel area

Steady drag (lift) coefficient for jth cylinder

Perfodic fluctuating dirag (lift) coefficient for the $j$ th cylinder

Added-inass coefficient

Drag coefífient

Viscous damping coefficient of a structure

Two-pha:e flow damping coefficient

Viscous damping coefficient

Diameter of cylinder

Flexural rigidity of cylinder

Oscillation frequency

Natural frequency in fluid

Natural frequency in vacuum

Fluid force component

Fluid force component in the $x$ direction of the $j$ th cylinder

Fluctuating fluid force component in the $x$ direction of the jth cylinder

Fluid force component in the $y$ direction of the $j$ th cylinder

Fluctuating fluid force component in the $y$ direction of the jth cylinder

Cylinder length

Cylinder mass per untt length

Added mass

Mass per unit length of cylinder $j$

Displaced mass of fluid or mass of fluid inside a pipe

Number of cylinders in an array

Pitch

Flow rate

Reynolds number

Time

Axial tension, transverse pitch

Cylinder displacement

Displacement of the $j$ th cylinder in the $x$ direction 


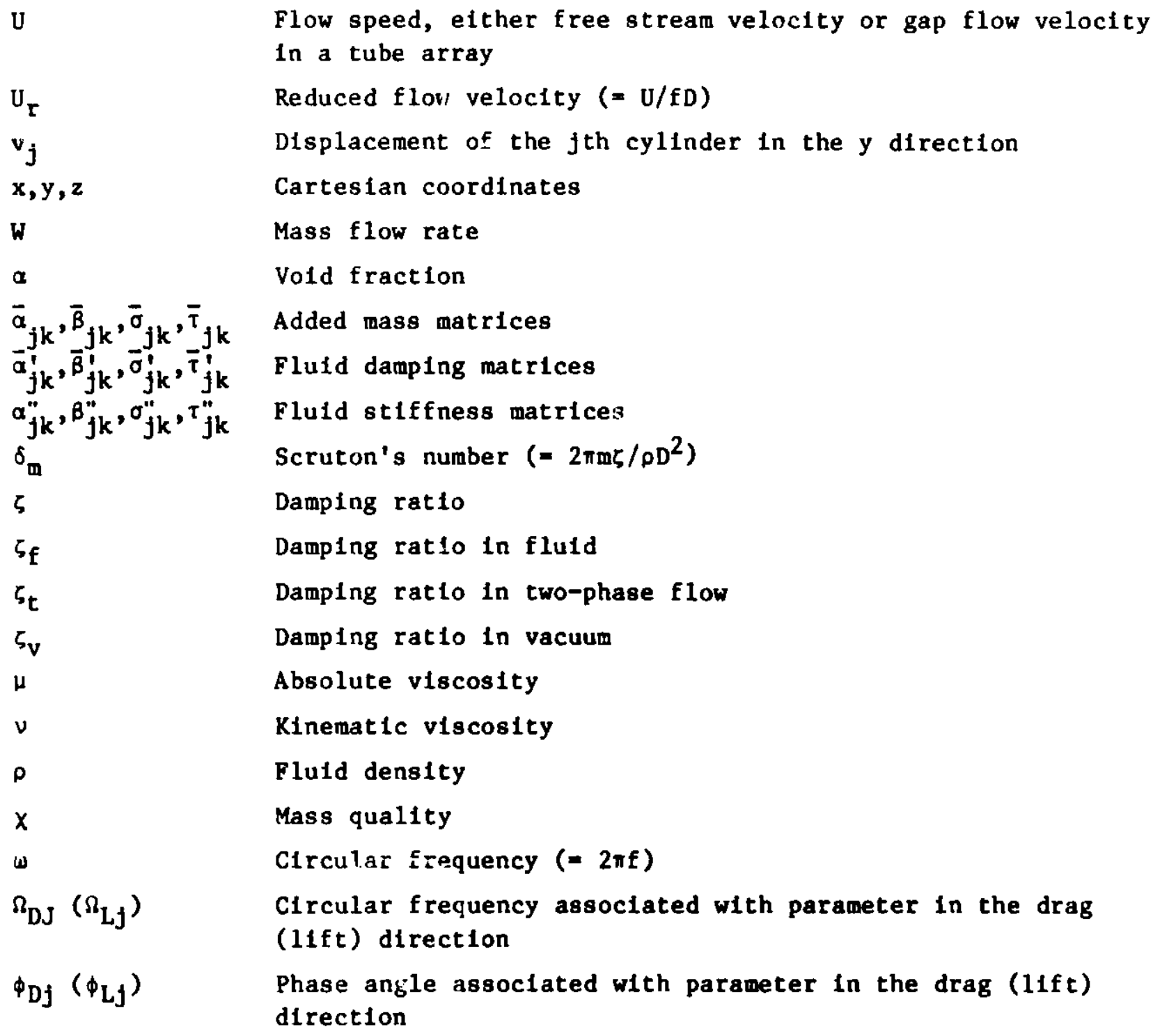




\section{CREDITS}

The author and Argonne Natfonal Laboratory gratefully acknowledge the courtesy of the organizations and Individuals who granted permission to use illustrations and other information in this report. The sources of this information are 11 sted below.

Fig. I

Fig. 2

Fig. 4

Figs. 5, 6

F1g. 7

F1gs. 8, 9

F1g. 10
"Damping and Hydrodynamic Mass of a Cylinder in Simulated Two-Phase Flow," L. N. Carluccl, ASME J. Mech. Des. 102, 597-602, 1980, Fig. 10. Permission granted by the American Soclety of Mechanical Engineers.

"Experimental Studies of Damping and Hydrodynamic Mass of a Cylinder in Confined Two-Phase Flow," L. N. Carluccl and L. D. Brown, J. Vibration, Acoust., Stress and Rellability in Des. 105, 83-89, 1982, Fig. 8. Permission granted by the American Soclety of Mechanical Engineers.

"Two-Phase Cross-Flow-Induced Forces Acting on a Circular Cylinder," F. Hara, ASME Publication PVP Vo1. 63, pp. 9-17, 1982, Photo 1. Permission granted by the American Society of Mechanical Engineers.

"Two-Phase Buffeting of Heat Exchanger Tubes," H. G. D. Goyder, Proc. Int. Conf. Flow Induced Vibrations, 12-14 May, 1987, Bowness-on-W1ndermere, England, Paper No. E2, pp. 211-222, F1gs. 1 and 2. Permission Granted by BHRA, The Fluld Englneering Centre, Cranfield, Bedford, England.

"A1r-Bubble Ef fects on Vortex-Induced Vibrations of a Circular Cylinder," F. Hara, Symp. Flow-Induced Vibrations, Vol. 1, 1984, pp. 103-113, Figs. 3 and 5. Permission granted by the American Society of Mechantcal Englneers.

"Vibration of a Single Row of Circular Cylinders Subjected to Two-Phase Bubble Cross-Flow," F. Hara, Proc. Int. Conf. Flow Induced Vibration, 12-14 May, 1987, Bowness-on-Windermere, England, Paper No. E1, pp. 203-210, Figs. 10 and 12. Permission granted by BHRA, The Fluld Englneering Centre, Cranfleld, Bedford, England.

\footnotetext{
"Experimental Study of Single- and Two-Phase Flow Fields Around PWR Steam Generator Tube Support Plates," J. M. Bates and C. W. Stewart, EPRI NP-1142, Project 1121, August 1979, F1g8. 5-5, 5-6, 5-7, 5-8, 5-9, and 5-10. Permission granted by Electric Power Research Inst1tute.
} 
Figs. 11, 12

Fig. 13
"An Analytical and Experimental Investigation of the Vibration of Cylindrical Reactor Fuel Elements in Two-Phase Parallel Flow," Nucl. Sci. Eng. 44, 277-290, 1971, Figs. 6 and 9. Permission granted by American Nuclear Society.

"Two-Phase Flow Induced Parametric Vibrations in Structural Systems, Pipes and Nuclear Fuel Pins," Rep. of the Inst. of Ind. Sci. Univ. Tokyo, 28, Serial No. 183, 1980, Fig. 4.5. Permission granted by the University of Tokyo. 


\title{
A REVIEW OF TWO-PHASE PLOW-INDUCED VIBRATION
}

\author{
S. S. Chen
}

\begin{abstract}
Two-phase flow exists in many shell-and-tube heat exchangers and power generation components. The flowing fluid is a source of energy that can induce small-amplitude subcritical osclllations and large-amplitude dynamic instabilities. In fact, many practical system components have experienced excessive flowInduced vibrations. To prevent unacceptable flow-induced vibration, we must understand excitation mechanisms, develop analytical and experimental techniques, and provide reliable design guidelines. Thus, we are conducting a comprehensive program to study structural vibration in components subjected to two-phase flow. This report reviews the current understanding of vibration of circular cylinders in quiescent fluid, crossflow, and axial flow, with emphasis on excitation mechanisms, mathematical models, and avaflable experimental data. A unified theory is presented for cylinders oscillating under different flow conditions. Based on the theory, future research needs are outlined.
\end{abstract}

\section{INTRODUCTION}

Two-phase flow exists in a wide varlety of engineering systems, including power, heat transfer, process, and transport systems. For example, in a typical U-tube steam generator, the exit flow in the U-bend region is composed of a water and steam mixture. A flowing two-phase fluld ts a source of energy that can Induce and sustain structural vibration and Instability. In fact, two-phase flow can induce oscillations that are very similar to those of single-phase flow and produce detrimental effects comparable to those of single-phase flow.

Based on the direction of flow with respect to the major axis of structural components, two-phase flow-induced vibration problems can be divided into two groups: axial flow, in which the flow direction is parallel to the structural axis; and crossflow, in which the flow direction is perpendicular to the structural axis. Both axlal-flow- and crossflow-1nduced vibrations have been studied in pest decades. A state-of-the-art review of axial flow, with emphasis on circular rods, was reported by Shin (1978), and a review of vibrations of circular cylinders in two-phase crossflow was reported by Hara (1987b). This report reviews two-phase flow-1nduced vibrations for crossflow as well as axial flow. The objective is to summarize the excitation mechanisms, mathematical models, response characteristics, design considerations, and future research needs. 
Two models are frequently used for two-phase flow: the homogeneous flow model and the separated flow model. The homogeneous flow model is used in most cases for flow-1nduced vibration. If the cross sectional area of a channel is $A$ and the cross sectional area occupled by the gas and liquid phases are $A_{g}$ and $A_{\ell}$ respectively, where the subscripts $g$ and $\ell$ indicate gas and liquid respectively, then the vold fraction $\alpha$ is given by

$$
\begin{aligned}
& \alpha=\frac{{ }^{A} g}{A}, \\
& 1-\alpha=\frac{A_{\ell}}{A} .
\end{aligned}
$$

The mass flow rate 1 s represented by $W$ and will be the sum of the Individual phase flow rates $W_{g}$ and $W_{l}$. Thus, the mass quality (also referred to as mass dryness fraction) $\chi$ is defined as

$$
\begin{aligned}
& x=\frac{W_{g}}{W_{g}+W_{\ell}}, \\
& 1-x=\frac{w_{\ell}}{W_{g}+W_{\ell}} .
\end{aligned}
$$

The mean velocity of an Individual phase is denoted by $U$ and the density by $\rho$; thus

$$
\begin{aligned}
& \mathrm{U}_{g}=\frac{\mathrm{W}_{\mathrm{g}}}{\rho_{\mathrm{g}} \mathrm{A}_{\mathrm{g}}}, \\
& \mathrm{U}_{\ell}=\frac{\mathrm{W}_{\ell}}{\rho_{\ell} \mathrm{A}_{\ell}}, \\
& \frac{\mathrm{U}_{\mathrm{g}}}{\mathrm{U}_{\ell}}=\left(\frac{x}{1-\chi}\right)\left(\frac{\rho_{\ell}}{\rho_{g}}\right)\left(\frac{1-\alpha}{\alpha}\right) .
\end{aligned}
$$

The mean flow velocity of the mixture $U$ is given by

$$
U=\frac{W_{g}+W_{\ell}}{\rho A},
$$


where the mixture density is defined by

$$
\rho=(1-\alpha) \rho_{\ell}+\alpha \rho_{g}
$$

The Reynolds number is defined by

$$
\operatorname{Re}=\rho U / \mu
$$

where $D$ is cylinder diameter and the dynamic viscosity $\mu$ is determined by McAdams correlation (Colizer 1981):

$$
\frac{1}{\mu}=\frac{x}{\mu_{g}}+\frac{1-x}{\mu_{l}}
$$

Based on the homogeneous two-phase flow model and theory of elasticity, the dynamic fluid/structure interaction can be described by the same equation as that for single-phase flow (Chen 1987):

$$
[M]\{\ddot{Q}\}+[C]\{\dot{Q}\}+[K]\{Q\}=\{G\}
$$

or

$$
\left[M_{s}+M_{f}\right]\{\ddot{Q}\}+\left[C C_{s}+C_{f}\right]\{\dot{Q}\}+\left[K_{s}+K_{f}\right]\{Q\}=\{G\}
$$

where $\{Q\}$ is the generalized structural displacement; [M] is the mass matrix, including structural mass $\left[M_{s}\right]$ and added mass $\left[M_{f}\right] ;[C]$ is the damping matrix, including structural dampling $\left[C_{s}\right]$ and fluid damping $\left[C_{f}\right] ;[K]$ is the stiffness matrix, including structural stiffness $\left[K_{s}\right]$ and fluid stiffness $\left[K_{f}\right]$; and $\{G$ \} represents the other excltation forces, Including vortex shedding, turbulence, and acoustic nolses.

In general, $M, C, K$, and $G$ are functions of $Q, \dot{Q}$, and $\ddot{Q}$; therefore, a complete solution is rather difficult to obtain. Fortunately, in most practical situations, one can ignore all nonlinear terms that make $M, C, K$, and $G$ dependent on structural response. However, even in a linear case, it is still not possible to obtain $M_{f}, C_{f}, K_{f}$, and $G$ for most situations.

Once the two-phase fluid mass, damping, stiffness, and excitation are known, Eq. (9) can be solved in a stralghtforward manner. The major task is to obtain these fluid matrices and excitation forces for various flow conditions. For small-amplitude oscillations, $M_{f}$ and $C_{f}$ are important for 
structures oscillating in a quiescent fluid; in cross and axial flows, $M_{f}, C_{f}$, $\mathrm{K}_{\mathrm{f}}$, and $\mathrm{G}$ are important. In this report, examination of the various excitation mechanisms is based on the consideration of these fluid-force matrices.

It should be noted that Eqs. (8) and (9) are approximate for structural response in two-phase flow. All fluld effects are incorporated in $M_{f}, C_{f}, K_{f}$, and G. In most cases, the equations are acceptable. However, in some situations, they may not be adequate. Their applicability and linitations are not well known at present. Modeling these fluid effects in two-phase flow and establishing the range of applicablilty of the models are toples for future research studies.

\section{ADDBD MAS AND DAYPING}

The added mass and damping for a circular cylinder osctllating in twophase flow has been studted based on the homogeneous model [Carlucci (1980), Carlucel and Brown (1983), Hara and Kahgo (1982) and (1986), Pettigrew and Tromp (1985)]. When such a clrcular cylinder has a displacement value $u$, the fluid force $g$ acting on it is given by the equation

$$
g=-\mathbf{m}_{a} \frac{\partial^{2} u}{\partial t^{2}}-c_{v} \frac{\partial u}{\partial t},
$$

where $m_{a}$ is the added mass and $C_{v}$ is the fluid damping.

The added mass $\mathrm{m}_{\mathrm{a}}$ of a single cylinder in two-phase flow is given by

$$
m_{\mathbf{a}}=C_{m^{M}} \mathbf{d}_{d}
$$

where $C_{m}$ is the added-mass coefficient and $M_{d}$ is the displaced mass of fluid. Experimental data for a single cylinder in an annular region indicate that the added-mass coefficient for two-phase flow is the same as that for singie-phase flow. A summary of the results for single-phase flow has been reported [Chen and Chung (1976)].

The added mass for two-phase flow is calculated from the homogeneous model; 1.e., it is equal to the displaced volume of fluld multiplied by the effective fluid density $p$. Theoretical and experimental studies have been performed to quantify $\rho$. Typlcal experimental data are shown in Fig. 1 [Carlucc1 (1980)], where the rat1o of the effective density to the singlephase flow density $\rho_{\ell}$ is plotted as a function of vold fraction $\alpha$.

Several theories for the effective density have been summarized by Schumann (1981): 


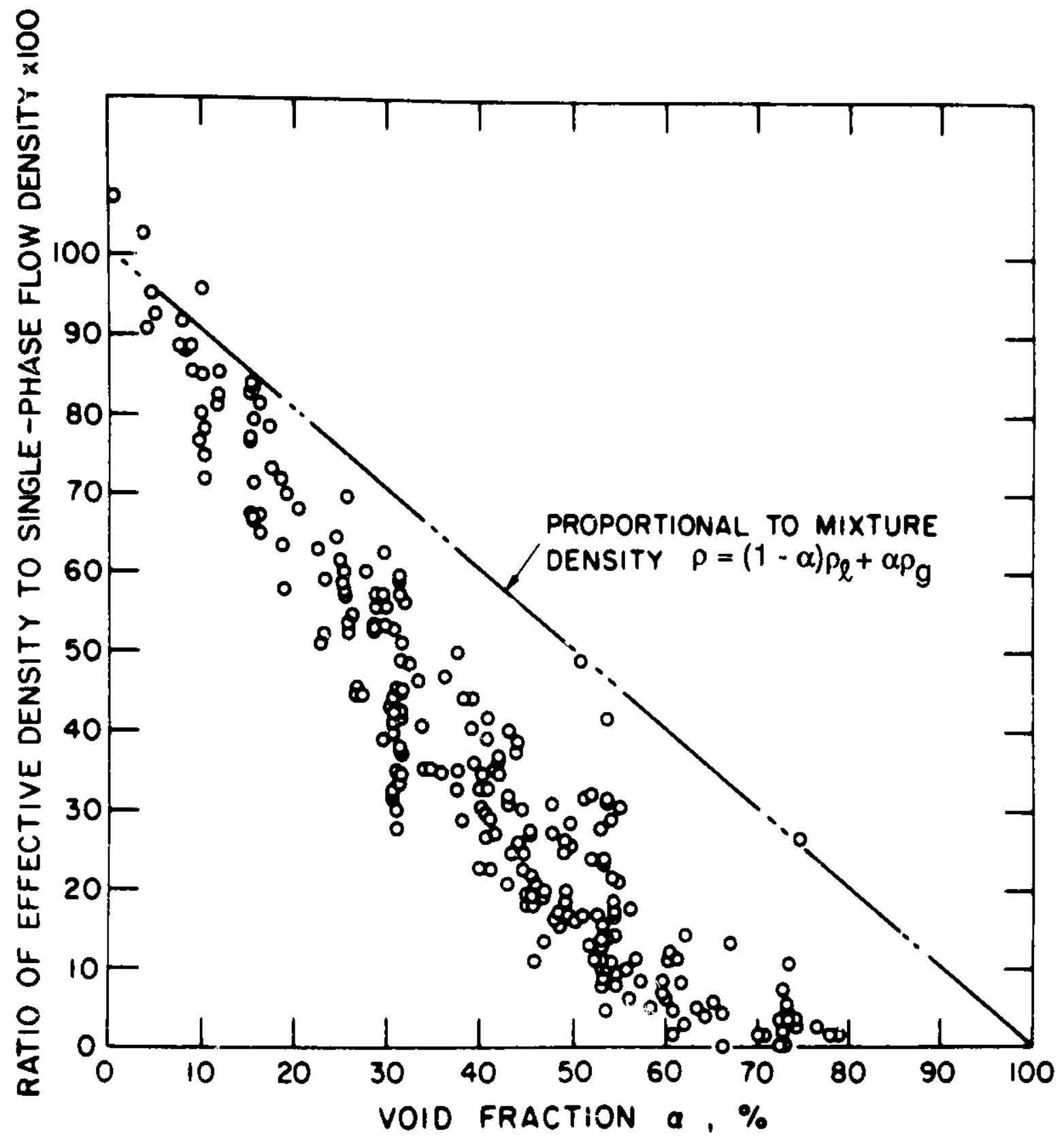

F1g. 1. Effectira density for two-phase flow as a function of vold fraction [from Carlucci (1980), with permission] 

(a) $\rho=(1-\alpha) \rho_{\ell}+\alpha \rho_{g}$,
(b) $\rho=\rho_{\ell}(1-\alpha) \prime(2 \alpha+1)$,
(c) $\rho=\rho_{\ell}(1-\alpha)(1+2 \alpha) /\left(1+4 \alpha-2 \alpha^{2}\right)$.

The first of these equations represents the volumetrically averaged mixture density; the other two are approximate virtual density formulas. The theoretical results obtalned from Eq. (12a) are presented in Fig. 1 to facilitate comparison with the experimental data. According to Eq. (12a), for a homogeneous two-phase mixture without slip, the effective density decreases IInearly with the void fraction $\alpha$; at low values of $\alpha$, it agrees well with the experimental data. For larger $\alpha$, the mixture density does not agree well with the data; the effective density is less than the averaged density. The other two theorles represented in $\mathrm{Eq}$. (12) correlate well with experimental data for the middle range of $\alpha$, but do not agree well with the data obtained when $\alpha$ is close to 0 or 1 .

There are several reasons for the discrepancies between the theory and experimental data:

- Nonhomogeneity: The gas phase is not uniformly distributed in twophase flow. For example, in the bubbly flow regime, the gas bubbles may stay close to the vibrating cylinder and reduce the effective density. In addition, at vold fractions of 60 to 80 percent, the flow regime is essentlaliy annular and the central portion of the flow passage is occupled largely by the gas phase.

effect.

- Compressibility: Gas phase compressibility affects the inertia

- Slip Between the Phases: The two phases of fluid are not moving at the same speed. Schumann's theory (1981) predicts that if there is slip between phases, the effective density is lower than the mixture density. The detalled mechanism(s) of how added mass causes deviation from the mixture theory has not been established.

Although fluid damping in a two-phase flow was studied experimentally by Carlucci and Brown (1983), hara and Kohgo (1982, 1986), and Pettigrew et al. (1985), the damping mechanisms operating in two-phase flow are not well understood. Experimental studies have been performed for a single cylinder in an annular region and for tube arrays. Mathematically, the viscous damping coefficient $c_{v}$ for two-phase flow is represented by

$$
C_{v}=C_{v}^{\prime}+C_{t}
$$


where $C_{v}^{\prime}$ is the damping coefficient attributed to the viscous effect and $C_{t}$ is the two-phase flow damping coefficlent.

$\mathrm{C}_{\mathrm{y}}^{\prime}$ can be calculated on the basis of methods derlved for single-phase flow [Chen et al. (1976)]. However, when doing so, the effective fluid density and viscosity should be used. The effective fluid density based on the mixture theory is given in Eq. (5) and the mixture viscosity according to McAdams is given in Eq. (7) [Collier (1981)]. There is no analytical expression for $C_{t}$. The most complete experimental data, those of Carlucci and Brown (1980), are given in Fig. 2. With Fig. 2, the two-phase damping coefficient $C_{t}$ can be calculated based on $C_{v}^{\prime}$.

In addition to the mixture theory, a mathematical model was developed by Hara and Kohgo (1986) to calculate the added wass and damping for a single cylinder oscillating in two-phase flow. The bubble flow is modeled as gas columns parallel to the vibrating cylinder. The gas columns are assumed to have neither mass nor rigidity. Small-amplitude oscillations of the cylinder and gas columns in fluid are then solved analytically. The added mass is based on the ideal flow theory and the damping on linearized viscous flow theory. Analytical and experimental results agree reasonably well.

The experimental technique for measuring the added mass and flufd-damping in two-phase flow is the same as that for single-phase flow. The natural frequencies and modal damping ratio in vacuum and in two-phase flow can be measured separately; these values are represented by $f_{v}$ and $f_{f}$, and $\zeta_{v}$ and $\zeta_{f}$. If the mass of the cylinder per unit length is $m$ and the viscous damping coefficient in vacuum is $C_{s}$, the added mass and fluid damping are given by

$$
m_{a}=m\left(\frac{f^{2}}{f_{f}^{2}}-1\right)
$$

and

$$
c_{v}=c_{s}\left[\frac{\zeta_{f}}{\zeta_{v}}\left(\frac{m+m_{a}}{m}\right)^{0.5}-1\right] \text {. }
$$

Th1s technique has been used for a single cylinder [Chen and Chung (1976)]

Although a single added mass $m_{a}$ and damping coefficient $C_{v}$ are sufficient to characterize the effect of two-phase flow on a single cylinder, the characterization of an array of $\mathrm{N}$ cylinders requires $4 \mathrm{~N}^{2}$ added masses and $4 \mathrm{~N}^{2}$ fluid damping coefficients. For example, consider an array of $\mathrm{N}$ cylinders as shown in Fig. 3. The axes of the cylinders are parallel to the $z$ axis. The subscript $j$ is used to denote variables assoclated with cylinder $j$. The displacement components of cylinder $j$ are $u_{j}$ and $v_{j}$ and the fluid force components are $g_{j}$ and $h_{j}$. Mathematically, the fluld force components assocfated with cylinder motion can be written [Chen (1987)] as follows: 


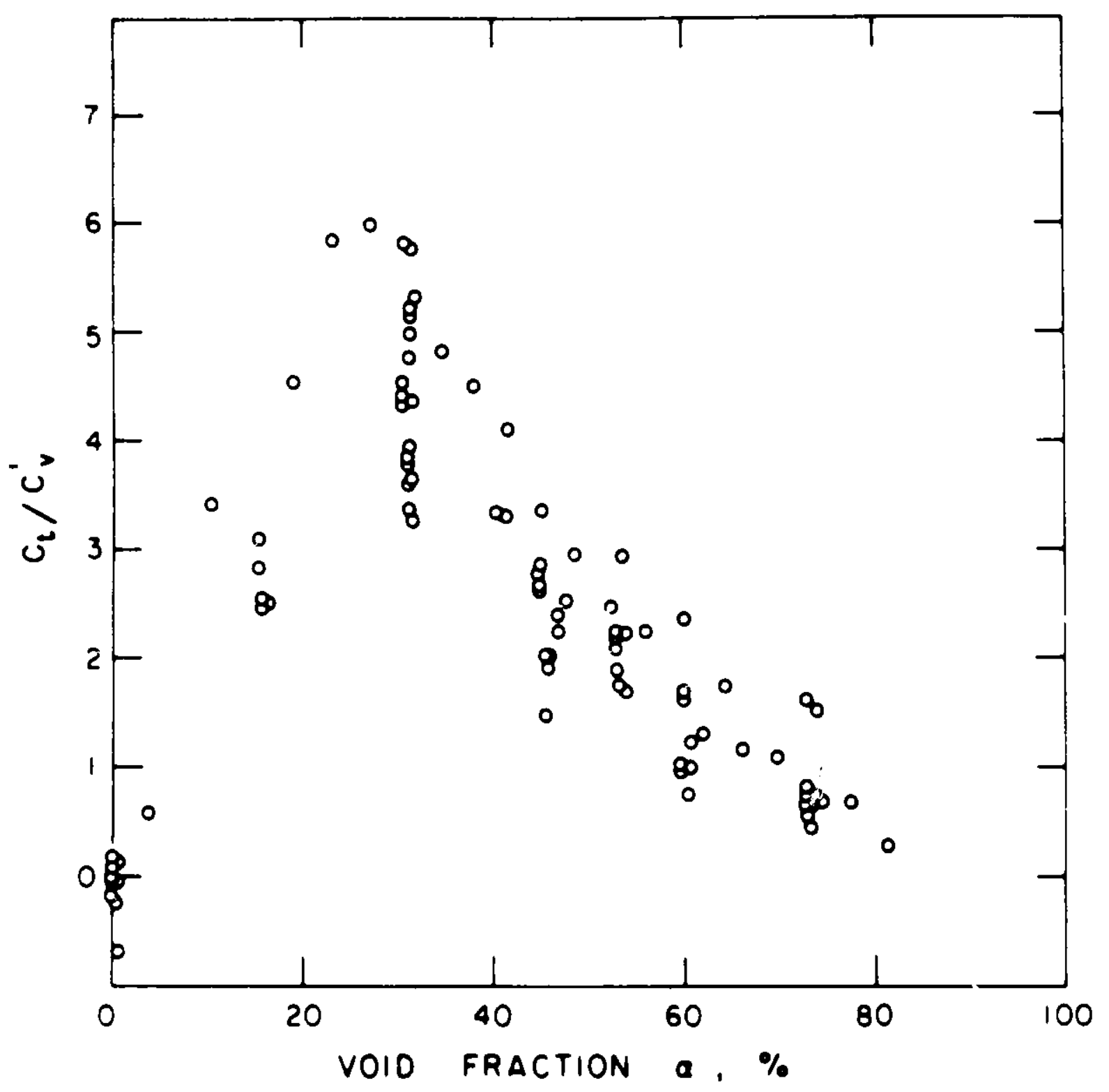

F1g. 2. Two-phase flow damping coefficient [from Carlucci and Brown (1982), with permission] 


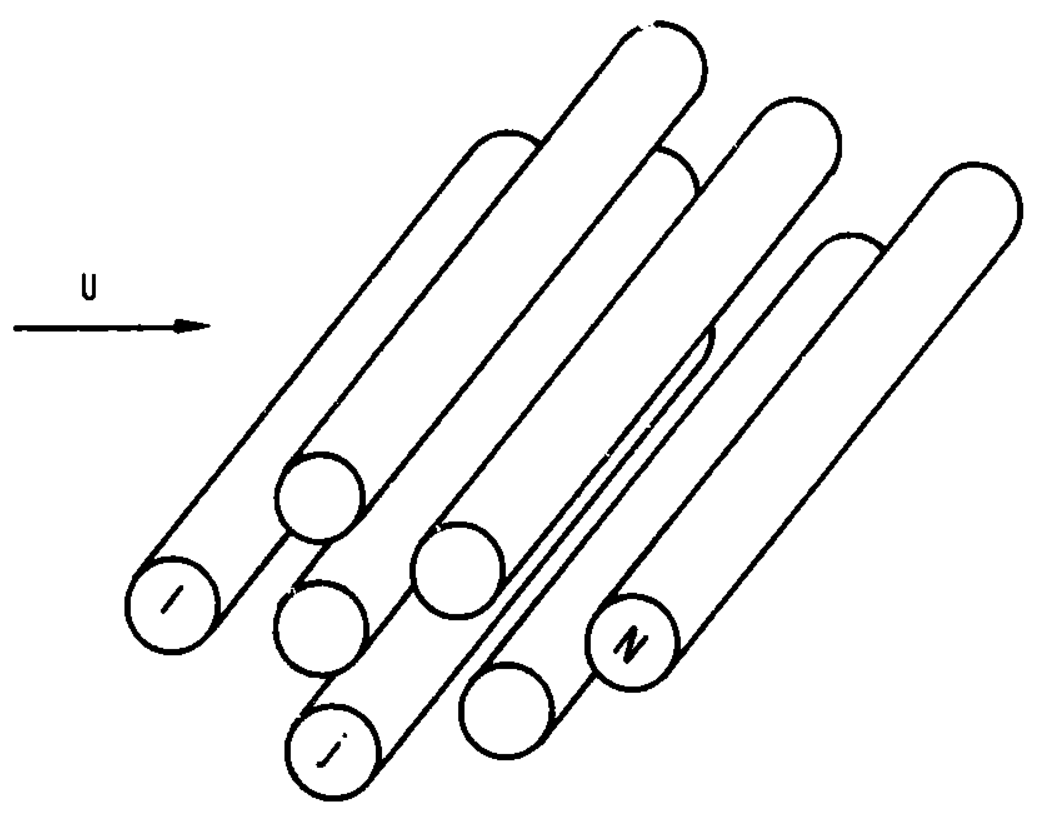

(o) A GROUP OF CIRCULAR CYLINOERS

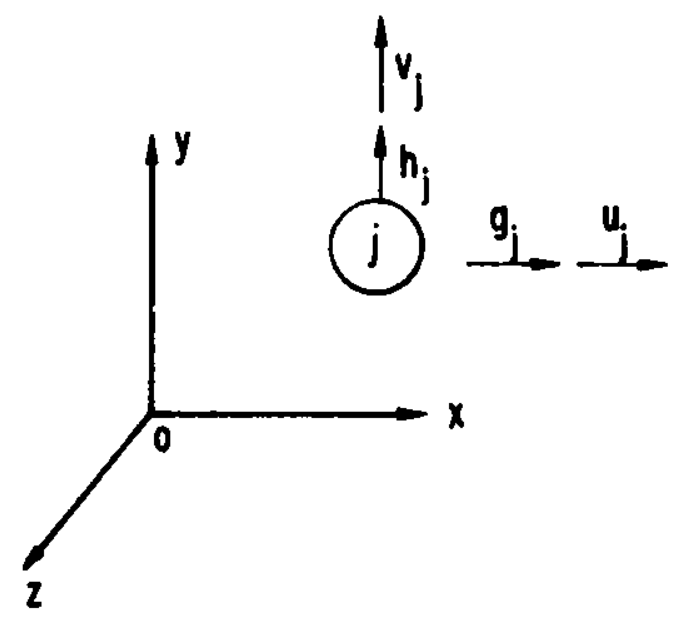

(b) FLUID FORCE AND CYLINDER DISPLACEMENT COMPONENTS

1g. 3. A group of circular cylinders in fluid 


$$
g_{j}=-\sum_{k=1}^{N}\left[\left(\bar{\alpha}_{j k} \frac{\partial^{2} u_{k}}{\partial t^{2}}+\bar{u}_{j k}^{\prime} \frac{\partial u_{k}}{\partial t}\right)+\left(\bar{\sigma}_{j k} \frac{\partial^{2} v_{k}}{\partial t^{2}}+\bar{\sigma}_{j k}^{\prime} \frac{\partial v_{k}}{\partial t}\right)\right],
$$

and

$$
h_{j}=-\sum_{k=1}^{N}\left[\left(\bar{\tau}_{j k} \frac{\partial^{2} u_{k}}{\partial t^{2}}+\bar{\tau}_{j k} \frac{\partial u_{k}}{\partial t}\right)+\left(\bar{\beta}_{j k} \frac{\partial^{2} v_{k}}{\partial t^{2}}+\bar{\beta}_{j k} \frac{\partial v_{k}}{\partial t}\right)\right],
$$

where $\vec{\alpha}_{j k}, \bar{\sigma}_{j k}, \bar{\tau}_{j k}$, and $\bar{\beta}_{j k}$ are added mass matrices and $\bar{\alpha}_{j k}^{\prime}, \bar{\gamma}_{j k}^{\prime}, \bar{\tau}_{j k}^{\prime}$ ' and $\bar{\beta} j k$ are flulci-damping matrices. These results are the same as those for single-phase flow. However, at this time, no analytical or experimental data are avallable for two-phase flow. It is expected that the added-mass matrices can be calculated on the basis of the potential flow theory, which has been successfully used for single-phase flow, provided the effective fluid density is used. Two-phase fluid damping remains a difficult parameter to predict or measure for the case of a cylinder array.

It is apparent that even for a single cylinder oscillating in two-phase flow, the added mass and damping for different flow regimes are uot well understood. For a general case of cylinder arrays, there are no data avallable for the added-mass and fluid-damping matrices. Although tube arrays have been tested [e.g., Pettigrew et al. (1985)], no attempts have been made to obtain the coupling effect. Thus, the coupling effect is a subject that requires further study if one wishes to predict the response of a cylinder array in two-phase flow.

Studies of added mass and damping have considered small oscillation amplitudes. In single-phase flow, as long as the oscillation amplitude is less than approximately 0.4 times the cylinder diameter, the linear theory given In Eqs. (10) and (15) is applicable [Skop et al. (1976)]. Data for both small- and large-amplitude osclilations in two-phase flow are lacking.

Once the added-mass and fluld-damplng matrlces are known, the response of cylinders oscillating in a two-phase fluid can easily be calculated by using Eq. (9). In a stationary fluid, the equation of motion 18

$$
\left[M_{s}+M_{f}\right][\ddot{Q}\}+\left[C C_{s}+C_{f}\right]\{\dot{Q}\}+\left[K_{s}\right]\{Q\}=\{G\}
$$

In a single-phase fluid, $M_{f}$ and $C_{f}$ are symmetrlc matrices. In a two-phase fluid, the characteristics of $M_{f}$ and $C_{f}$ are not known.

The Interaction of two-phase flow with a vibrating cylinder is dependent on the different flow regimes. In addition, cylinder osclilations may affect phase distribution. The detalled physics of the interaction of cylinders and two-phase flow is extremely complicated. Much more detalled studies, 
Including flow visualization, are needed to understand the interaction process.

\section{CROSSPLOH-INDUCED VIBRATION}

Two-phase crossflow-induced vibration of circular cylinders has recently been studied in several countries. As shown in Table 1, with the exception of the tests by Axlsa et a1. (1984, 1985, 1986), all tests were performed for alr-water flow. The main objective of these studies has been to determine the response of cylinder arrays in two-phase flow with the emphasis on 1dentifying the critical flow velocity. Several investigations have been conducted to measure the fluid excitation forces: Hara (1982), for a single cylinder; and Nakamura et al. (1982) and Taylor et a1. (1986), for cylinder arrays.

\section{Void Fraction}

Typlcally, the volume ratio $\beta$ of the two phase flow is established by metering the two types of fluid individually prior to mixing at the test section. The assumption of a homogeneous mixture implies that the two phase velocities are the same, in which case, the volume flow ratio $(\beta)$ and the void fraction $(\alpha)$ are the same. Several studies include measurements of void fraction upstream or downstream of the bundle as well as Inside the bundle.

Axisa et al. (1984) measured the vold fraction at five locations along the cylinder axis, but only at the upstream and downstream of the cylinder array. The vold fraction is determined as a function of mass quality $x$. In general, the flow is not homogeneous across the test section. For a fixed mass quality at low flow velocities, the local vold fraction is smaller at the center of the test section than at a location close to the wall. As flow velocity increases, the vold fraction is falrly unfform across the test channel. At low flow velocity, the averaged spatial vold fraction $\bar{\alpha}$ is smaller than the homogeneous vold fraction $\alpha$, but the difference between $\bar{\alpha}$ and $\alpha$ decreases with increasing flow velocity. Measurements of these values at upstream and downstream of the tube bundle are similar and tests in air-water and steam-water flows display simllar trends.

Remy (1982) measured the vold fraction between the fourth and fifth rows of a square array with $P / D=1.44$. Results show the very well-organized characteristics of the flow. The void fraction exhibits a periodic variation with the same perlod as the cylinder pitch. Furthermore, the variations change with flow velocity. At low velocities, a maximum vold fraction occurs at the gap of the array. But at large flow velocities, there are two maxima, one in the gap and the other in the wake of the cylinders. Although vold fraction within an array of cylinders varles, the averaged vold fraction value in a section is the same as the corresponding values upstream or downstream of the bundles. 
Table 1. Tests on two-phase crossf low-1nduced vibration

\begin{tabular}{|c|c|c|c|c|c|}
\hline Authors & Fluid & $\begin{array}{l}\text { Flow Regines } \\
\text { or } \\
\text { Vold Fraction }\end{array}$ & Test Section & Instrumentation & $\begin{array}{l}\text { Measured } \\
\text { Parameters }\end{array}$ \\
\hline $\begin{array}{l}\text { Axisa et al. } \\
(1984)\end{array}$ & $\begin{array}{l}\text { Air and water, } \\
\text { Stean and water }\end{array}$ & $0,91 z-100 x$ & $\begin{array}{l}\text { Square array, } \\
P / D=1.14\end{array}$ & $\begin{array}{l}\text { Y-ray densitometers, } \\
\text { Accelerometers, } \\
\text { Strain gauges }\end{array}$ & $\begin{array}{l}\text { Void fraction, } \\
\text { Tube response, } \\
\text { Damping }\end{array}$ \\
\hline $\begin{array}{l}\text { Axisa et al. } \\
(1985)\end{array}$ & Steam and water & $0,85 x-100 x$ & $\begin{array}{l}\text { Square array, } \\
\text { Triangular array, } \\
\text { P/D }=1.44\end{array}$ & $\begin{array}{l}\text { Strain gauges, } \\
\text { Accelerometers }\end{array}$ & $\begin{array}{l}\text { Tube displacement, } \\
\text { Damping }\end{array}$ \\
\hline $\begin{array}{l}\text { Axisa et al. } \\
(1986)\end{array}$ & $\begin{array}{l}\text { Air and water, } \\
\text { Stean and water }\end{array}$ & $0,50 \%-100 \%$ & $\begin{array}{l}\text { Straight tubes: } \\
\text { Single tube, } \\
\text { Tube row, } \\
\text { Square array } \\
\text { U-Tubes: Square } \\
\text { array, } \\
\text { P/D = } 1.44\end{array}$ & $\begin{array}{l}\gamma \text {-ray densitometers, } \\
\text { Accelerometers, } \\
\text { Strain gauges }\end{array}$ & $\begin{array}{l}\text { Void f raction, } \\
\text { Tube displaceraent, } \\
\text { Damping }\end{array}$ \\
\hline $\begin{array}{l}\text { Goyder } \\
\text { (1987) }\end{array}$ & Air and water & $\begin{array}{l}0,50 x-80 x \\
\text { and } 100 x\end{array}$ & $\begin{array}{l}\text { Triangular array } \\
P / D=1.25\end{array}$ & Load cells & $\begin{array}{l}\text { Lift and drag } \\
\text { forces }\end{array}$ \\
\hline $\begin{array}{l}\text { Hara } \\
(1982,1984)\end{array}$ & Alr and water & Bubbles & Single tube & $\begin{array}{l}\text { Strain guages, } \\
\text { Pressure trans- } \\
\text { ducers, } \\
\text { Accelerometers }\end{array}$ & $\begin{array}{l}\text { Tube displacement, } \\
\text { Lift and drag } \\
\text { forces }\end{array}$ \\
\hline $\begin{array}{l}\text { Hara } \\
(1987 a)\end{array}$ & Air and water & $\begin{array}{l}\text { Bubbla, } \\
\text { Max. Re }=3.25 \times 10^{4}\end{array}$ & $\begin{array}{l}\text { Tube row, } \\
P / D=1.33\end{array}$ & Accelerometer & $\begin{array}{l}\text { Tube response, } \\
\text { Damping } \\
\delta_{\mathrm{m}}=3.09 \text { to } 4.72\end{array}$ \\
\hline $\begin{array}{l}\text { Heilker and } \\
\text { Vincent }(1980)\end{array}$ & Air and water & $0,50 z-87 \%$ & $\begin{array}{l}\text { Triangular array, } \\
\text { P/D = } 1.36 ; \\
\text { Square array, } \\
\text { P/D }=1.50\end{array}$ & $\begin{array}{l}\text { Accelerometers, } \\
\text { Strain gauges, }\end{array}$ & $\begin{array}{l}\text { Tube displacement, } \\
\text { Danping }\end{array}$ \\
\hline
\end{tabular}


Table 1. Tests on two-phase crussflow-1nduced vibration (Contd.)

\begin{tabular}{|c|c|c|c|c|c|}
\hline Authors & Fluid & $\begin{array}{l}\text { Flow Regimes } \\
\text { or } \\
\text { Void Fraction }\end{array}$ & Test Section & Instruinent at ion & $\begin{array}{l}\text { Measured } \\
\text { Yarameters }\end{array}$ \\
\hline $\begin{array}{l}\text { Nakanura } \\
\text { et al. } \\
(1982)\end{array}$ & Atr and water & $\begin{array}{l}\text { Bubble and } \\
\text { slug flow }\end{array}$ & $\begin{array}{l}\text { Square and } \\
\text { rotated square } \\
\text { array, } P / D=1.47\end{array}$ & Straln gauges & $\begin{array}{l}\text { Lift and drag } \\
\text { forces }\end{array}$ \\
\hline $\begin{array}{l}\text { Nakinura and } \\
\text { Fufita } \\
(1987)\end{array}$ & Ail $r$ and water & $\begin{array}{l}\text { Bubble and } \\
\text { slug flow }\end{array}$ & $\begin{array}{l}\text { Square array, } \\
\text { P/D = } 1.42 \text {, } \\
\text { One flexible cylinder } \\
\text { in a rigid tube } \\
\text { array }\end{array}$ & Strain gauges & $\begin{array}{l}\text { Tube displacement, } \\
\text { Damping }\end{array}$ \\
\hline $\begin{array}{l}\text { Petrigrew and } \\
\text { Gorman } \\
(1973,1978)\end{array}$ & Atr and water & $\begin{array}{l}0 \text { to } 95 \% \\
\operatorname{Re}=10^{4}-10^{5}\end{array}$ & $\begin{array}{l}\text { Trlangular array, } \\
\text { Re-cated tri- } \\
\text { angular array, } \\
\text { Square array, } \\
\text { Rotated square } \\
\text { array, } P / D=1.47\end{array}$ & Strain gauges & $\begin{array}{l}\text { Tube displacerent, } \\
\text { Damping }\end{array}$ \\
\hline $\begin{array}{l}\text { Pettigrew } \\
\text { et al. } \\
(1985)\end{array}$ & Air and water & 5 to $98 \%$ & $\begin{array}{l}\text { Trlangular and } \\
\text { Square array, } \\
P / D=1.47\end{array}$ & Strain gauge & $\begin{array}{l}\text { Tube displacerient, } \\
\text { Damping }\end{array}$ \\
\hline Remy (1982) & AIr and water & Bubble & $\begin{array}{l}\text { Square array, } \\
P / D=1.44\end{array}$ & $\begin{array}{l}\text { Accelerometers, } \\
\text { Optical fiber probe }\end{array}$ & $\begin{array}{l}\text { Void fraction, } \\
\text { Damping, } \\
\text { Tube response }\end{array}$ \\
\hline $\begin{array}{l}\text { Taylor et al. } \\
(1986)\end{array}$ & Air and water & $\begin{array}{l}0 \text { to } 95 \%, \\
\text { Re }=1.12 \times 10^{4} \\
\text { to } 1.24 \times 10^{5}\end{array}$ & $\begin{array}{l}\text { Tube row, } \\
y / D=1.5 \text { and } 3.0\end{array}$ & Force transducer & $\begin{array}{l}\text { Drag and lift } \\
\text { forces }\end{array}$ \\
\hline
\end{tabular}




\section{Added Mass and Damping}

The added mass of an array of cylinders in crossin low has not been studied in detafl. Although this is true for both single- and two-phase flows, twophase flow data are especially limited. For practical purposes, there are no complete sets of data for added-mass matrices of an array of cylinders. The results obtained when Remy (1982) tested a flexible cylinder in a rigid square array can be used to calculate only the self-added mass $\bar{\alpha}_{j j}$ and $\vec{\beta}_{j j}$ [see Eq. (15)]. Other Investigators performed tests on a flexible cylinder array [Axisa et al. (1984) and Pettigrew et al. (1985)] but only the dominant coupled modes were considered. Therefore, the individual elements of the added-mass matrices are not considered by Axisa and Pettigrew. In order to obtain the added-mass matrices, motion-dependent fluid forces associated with the cylinder motion must be measured. No test results have been reported in the literature.

If a cylinder is oscillating in two-ohase flow, damping can be associated with different sources. Mathematically, it is conventent to separate the damping into several components:

$$
\zeta=\zeta_{s}+\zeta_{\mathrm{f}}+\zeta_{\mathrm{t}}
$$

where $\zeta$ is the total damping ratio, $\zeta_{\mathrm{S}}$ is the structural damping ratio, $\zeta_{\mathrm{f}}$ is the fluid viscous damping ratio for single-phase flow, and $\zeta_{t}$ is the twophase-flow damping ratio.

Fluid damping of single-phase flow consists of two parts: viscous damping and flow-velocity-dependent damping. Calculation of the viscous damping of two-phase flow, as discussed in Section II, can be based on the same method as single-phase flow. The flow-velocity-dependent damping can be calculated by the same method developed for a single cylinder in single-phase flow [Chen (1987)]:

$$
\begin{aligned}
\zeta_{f} & =\frac{C_{D}}{\pi^{2}}\left(\frac{M_{d}}{m+m_{a}}\right)\left(\frac{U}{f D}\right) \text { for drag direction, } \\
& =\frac{C_{D}}{2 \pi^{2}}\left(\frac{M_{d}}{m+m_{a}}\right)\left(\frac{U}{f D}\right) \text { for lift direction, }
\end{aligned}
$$

where $M_{d}$ is the displaced mass of fluld, $f$ is oscillation frequency, and $C_{D}$ is the drag coefficient. Equation (18) is applicable for an isolated cylinder at high reduced flow velocity. 
Axisa et al. (1984) used Eq. (18) to obtain the two-phase flow damping for a square array in air-water and steam-water two-phase flows. The results agree reasonably well with those measured for a single cylinder in quiescent fluid [Carlucci and Brown (1982)].

For an array of cylinders, the two-phase flow damping effect can also be described by Eq. (15), where $\bar{\alpha}_{j k}^{\prime}, \bar{\sigma}_{j k}^{\prime}, \bar{\tau}_{j k}^{\prime}$, and $\bar{\beta}_{j k}^{\prime}$ are attributed to viscous effects, flow-velocity-dependent components, and two-phase flow effects. The details for a cylinder array in crossflow are not well understood at this time.

\section{Pluid Excitation Forces}

Fluid excitation forces acting on circular cylinders were measured by Hara (1982) for a single cylinder, and by Nakamura et al. (1982), Taylor et al. (1986), and Goyder (1987) for an array of cylinders. In addition, flutd forces have also been computed from cylinder responses subjected to crossflow [Pettigrew and Gorman (1973)].

Hara measured the unsteady $11 \mathrm{ft}$ and drag forces and the pressure fluctuation on a stationary cylinder immersed in a crossflow. The test, performed in an air-water two-phase flow, shows that the existence of vortex shedding for a single cylinder in crossflow depends on the void fraction. For $\alpha$ less than about $10 \%$, visualization of flow and measurement of $f$ luid pressure show the existence of vortex shedding in two-phase flow [see Fig. (4b)]. However, as $\alpha$ increases, the wavy motion of the wakes disappears [Fig. (4c)].

The characteristics of the pressure fluctuations and fluctuating drag and lift forces also depend on the vold fraction. For small $\alpha$, where vortex shedding exists, the pressure fluctuation and fluld forces vary insignificantiy with $\alpha$ and are similar to those of single-phase flow. Furthermore the lift force is narrow-banded and the drag force is less perlodic. Although for small $\alpha$, the bubbles implnging on the cylinder may produce a larger force compared with those for single-phase flow, the dominant frequency is that attributed to vortex shedding because Karman vortex shedding remains the dominant mechanism. On the contrary, when $\alpha$ is large, the motion of air bubbles in the flow may be random and the impinging frequency may be proportional to $\alpha$ and flow velocity. The lift and drag forces are of the same magnitude and contain high-frequency components. For large $\alpha$, vortex shedding disappears and the drag and lift forces depend strongly on the vold fraction.

Goyder (1987) measured the fluctuating drag and lift forces of a triangular array with a P/D of 1.25. Figures 5 and 6 show the time histories for $\alpha=70 \%$, and rms values as a function of flow velocity, respectively. Note that the peak amplitude of the drag force is much larger than that of the lift force. Furthermore, whereas the drag force exhibits peaks and is strongly asymmetric, the lift force is symmetric. The rms values of 1 ift and drag forces are approximately proportional to the velocity and are clearly dependent on the vold fraction $\alpha$. 

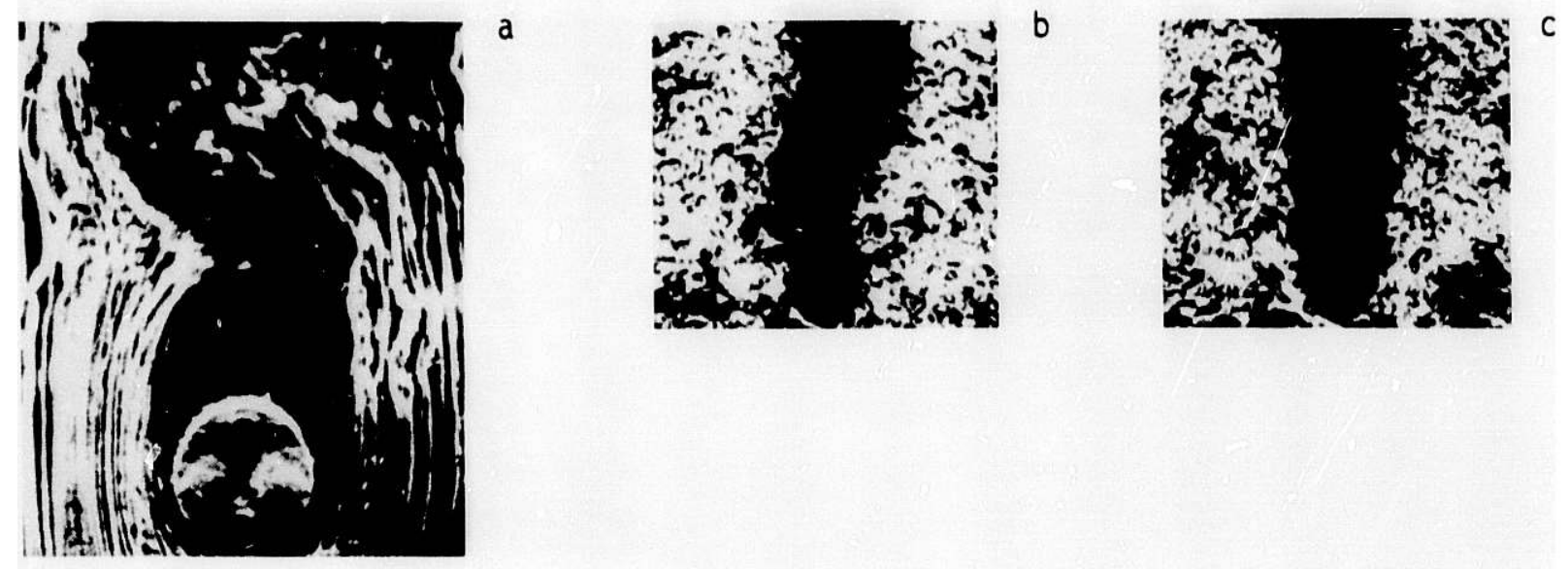

Fig. 4. Wake behind a cylinder: (a) water flow ( $U=0.4 \mathrm{~m} / \mathrm{s})$,

(b) oscillatory wake in two-phase flow ( $U=0.4 \mathrm{~m} / \mathrm{s}, \alpha=0.06)$,

(c) steady wake in two-phase flow ( $U=0.4 \mathrm{~m} / \mathrm{s}, \alpha=0.2$ ) [from Hara (1982), with permission] 

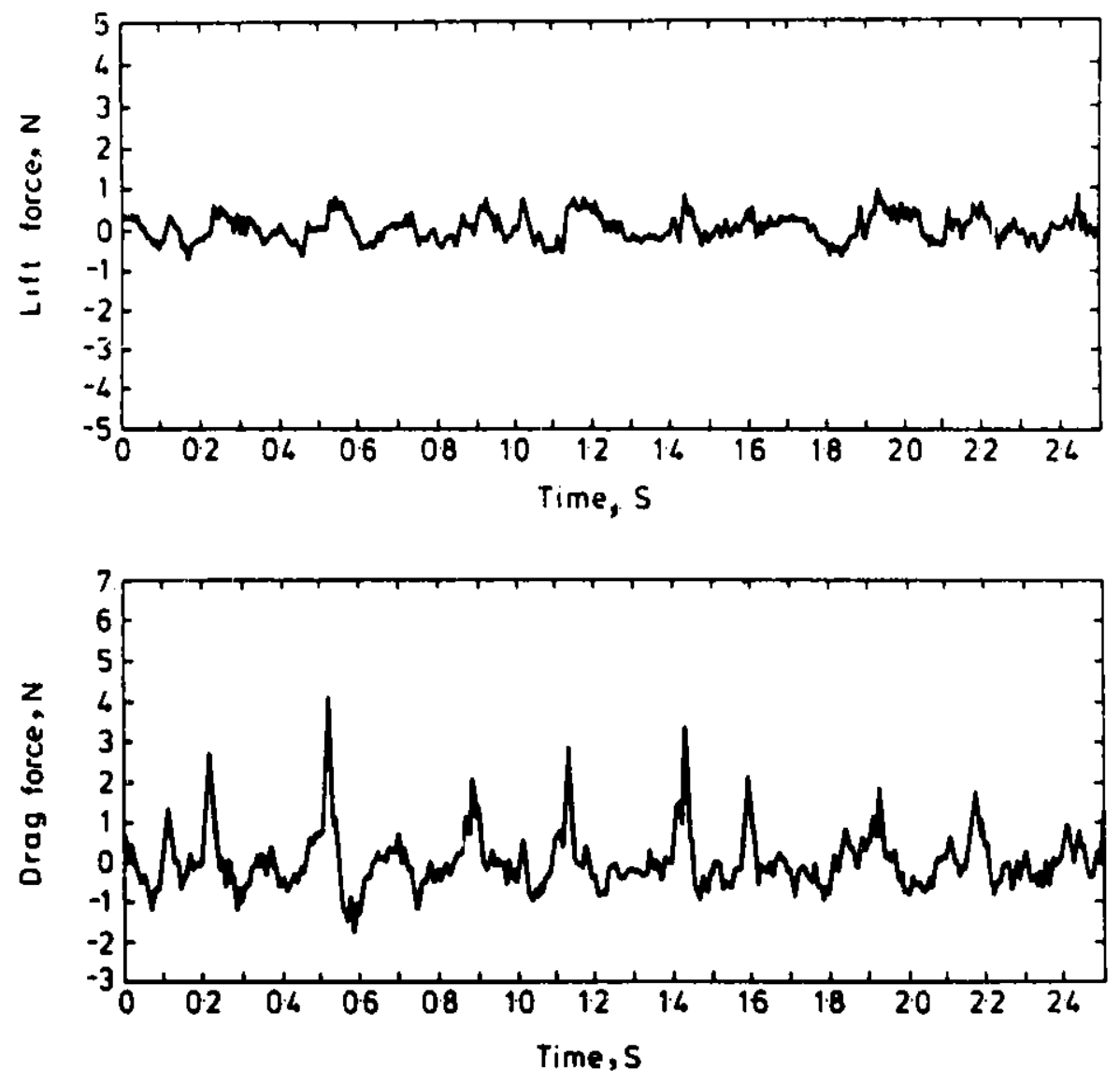

Fig. 5. Time histories of lift and drag forces for $\alpha=70 \%$ [from Goyder (1987), with permission] 

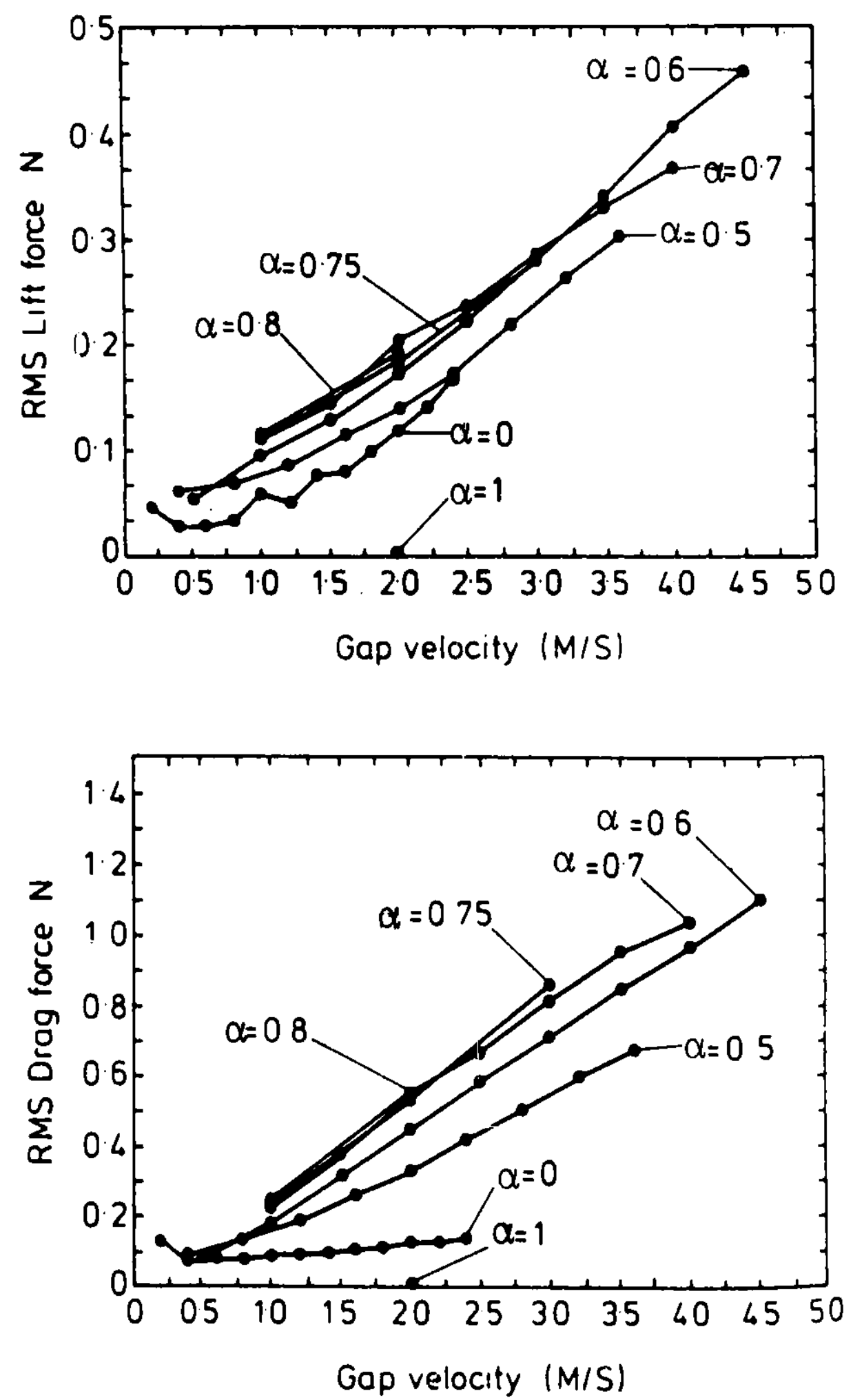

F1g. 6. RMS values of $11 \mathrm{ft}$ and drag forces as a function of gap velocity and vold fraction [from Goyder (1987), with permission] 
Nakamura et al. (1982) tried to characterize the excitation force and found that the characteristics of the forces depend on the flow regime. The cross spectral density of the excitation force $\Phi_{g g}\left(z, z^{\prime}, \omega\right)$ is considered to be the product of $R_{1}(z, w)$, determined by the position, and $R_{2}\left(z-z^{\prime}, w\right)$, the component that gives the correlation of two points:

$$
\Phi_{g g}\left(z, z^{\prime}, w\right)=R_{1}(z, \omega) R_{2}\left(z-z^{\prime}, \omega\right) .
$$

$R_{1}(z, \omega)$ is determined by the strength of the two-phase fluid force at each point. $R_{2}\left(z-z^{\prime}, \omega\right)$ is a function of distance. If the shapes of the power spectrum of excitation force are spatially homogeneous, $R_{1}(z, \omega)$ can be written

$$
R_{1}(z, \omega)=R_{1}(z) R_{1}(w),
$$

where $R_{1}^{\prime}(\omega)$ is normallzed such that

$$
\frac{1}{2 \pi} \int_{0}^{\infty} R_{1}^{\prime \prime}(\omega) \mathrm{d} \omega=1 .
$$

Nakamura et al. (1982) assumed that $R_{2}^{\prime \prime}\left(z-z^{\prime}, w\right)$ is 1 and $R_{j}^{\prime}(z)$ is a constant. Based on these assumptions, the following characteristics are noted.

- Excitation forces in two-phase flow can be classified according to flow pattern. In slug flow, liquid slugs flow intermittently at a rate of several times a second. The exciting force is mainly due to the bumping of liquid slugs against the cylinder, resulting in a large drag force and a lift force about $40 \%$ of the drag force. In bubble flow, the excitation force is reduced and 1 ts magnitude is equal to about 30 to $50 \%$ of the slug flow.

- The power spectra of excitation forces for bubble and slug flows are similar. In both cases, the frequency components at low frequency are high $(1-10 \mathrm{~Hz})$ and decrease with frequency. Cylinder location and arrangement do not have a significant effect on the power spectra.

- The rms drag and lift forces in a slug flow are independent of the superficial gas velocity and are proportional to the superfictal liquid velocity. (Superficial-phase velocity is defined as the velocity the phase would have if it flowed alone through the flow channe1). Taylor et al. (1986) obtained slmtlar results for a tube row with a P/D of 1.5 and 3.0. For $\alpha$ from 20 to $80 \%$, the spectra show a dominance of the drag force over the $11 \mathrm{ft}$ force. For low values of $\alpha$, the spectra are almost Identical to those of single-phase flow. 
In single-phase flow, the power spectral density of the fluid excitation force can be normalized by the dynamic pressure head multiplied by the cylinder length $\ell$ and cylinder diameter $D, i . e .$, as shown by Taylor et al. (1986) and Chen and Jendrzejczyk (1986):

$$
\Phi_{g g}(s)=\left[\frac{\Phi g}{\frac{g}{2} \rho U^{2} D \ell}\right]\left(\frac{U}{D}\right) .
$$

However, for two-phase flow, a nondimensional group of parameters has not been found to collapse the two-phase data.

In spite of the difficulty of normalizing the spectra, Pettigrew and Gorman (1978) use Eq. (22) to estimate the spectra of the fluid force coefficients in practical applications. The coefficients are inferred from tube response to two-phase flow.

\section{Structural Response}

The vibration of cylinders in two-phase flow is simllar to that in single-phase flow. Oscillations can be divided into three groups: vortexexcited oscillations, subcritical oscillations, and dynamic instability.

The response of a single cylinder in two-phase flow depends on the void fraction. Typical responses of a cylinder in the drag and lift direction obtained during a detalled study by Hara (1984) are given in Fig. 7. Singlephase flow can Induce large in-line oscillations when $U / f D \simeq 2.1$. When the void fraction is $5 \%$, the response amplitude is significantly reduced for $U_{r}$ from 0.5 to 2.5 ; in particular, at $U_{r}=2.1$, the amplitude is reduced to about $25 \%$ of that in water flow. As the vold fraction increases, the response amplitude increases. When $\alpha$ is large, the oscillation amplitude is very large compared with that in water flow $(\alpha=0)$.

The response in the crossflow direction of a single cylinder is different from the $1 \mathrm{n}-\mathrm{line}$ response. For $\alpha \leq 20 \%$, vibration amplitude increases almost linearly with $U_{r}$ up to $U_{r}=4.5$. For $U_{r}>4.5$, vibration amplitude decreases for $\alpha<10 \%$ and is almost a constant value for larger $\alpha$, e.g., $\alpha=20 \%$. Figure 7 shows that for $U_{r}>4.5$ the osclllation amplitude is drastically reduced by injecting a certain amount of air bubbles into the flow. For $\mathrm{U}_{\mathbf{r}}<4.5$, however, the two-phase flow-induced vibration is mach stronger than that excited by vortex shedding in water flow.

Based on data of Hara (1984), 1t may be concluded that the excitation mechanisms for a single cylinder are the buffeting forces due to the random motion of air bubbles in the flow and vortex shedding that generates a narrowbanded force on the cylinder at low $\alpha$. Furthermore, a small amount of air bubbles reduces the in-line and crossflow lock-1n resonances and a large amount of alr bubbles excltes large cylinder oscillations. 

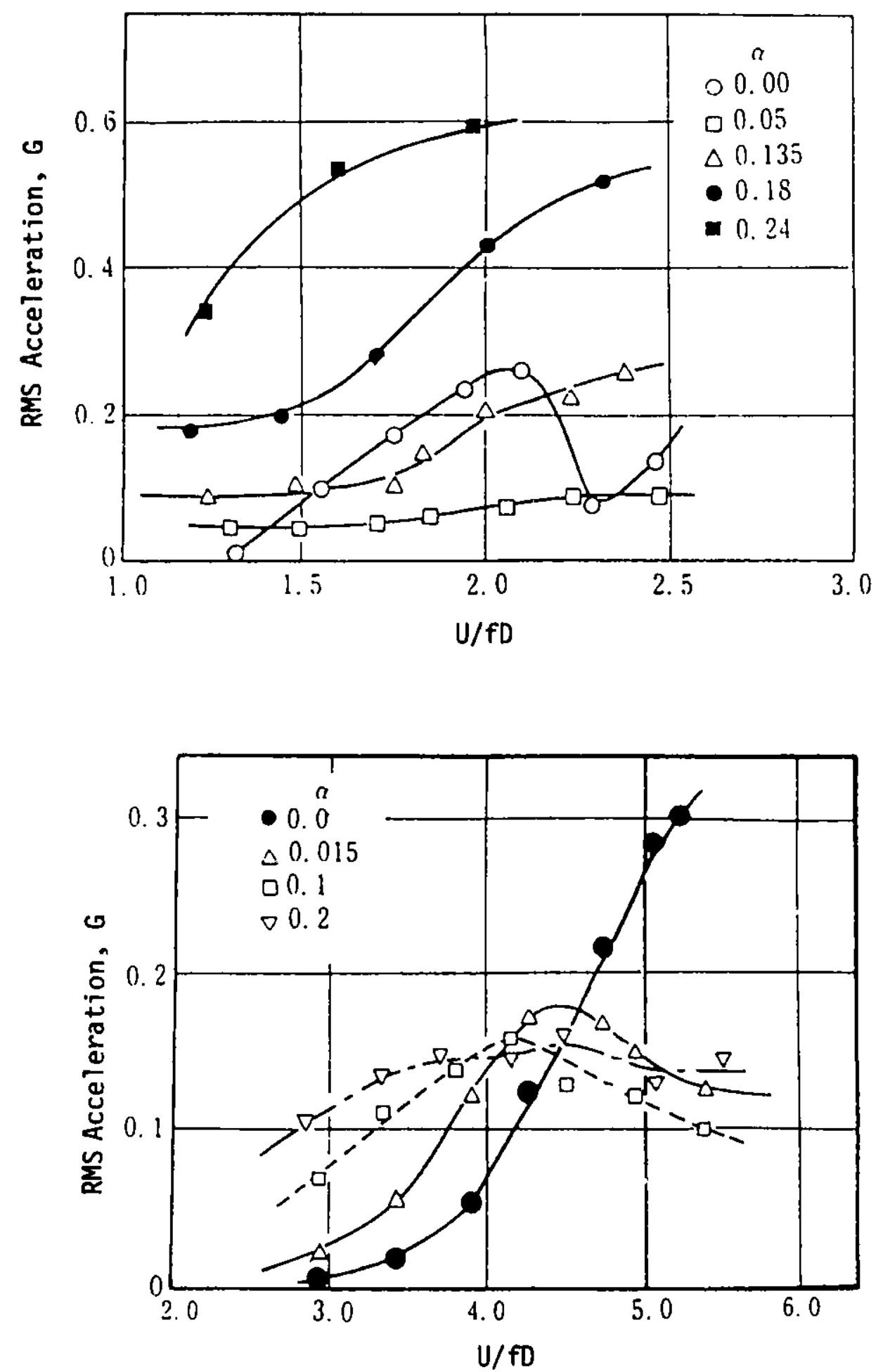

Fig. 7. The rms accelerations of a cylinder as a function of reduced flow velocity U/fD: (a) in-line direction; (b) crossflow direction [from Hara (1984), with permission] 
In a detalled study of tube rows subjected to crossflow, Hara (1987a) determined various vibrational characteristics and divided them into four types with respect to the effect of air bubbles on vibration. These are shown in Fig. 8 for four regions on the $\delta_{m}-U_{r}$ map and are described as follows:

(A) When the vold fraction is small, air bubbles excite random vibration, and the vibration amplitude increases with the void fraction.

(B) At high reduced flow velocity and large mass-damping parameter, air bubbles have little effect on cylinder response, but for $\alpha=20$ to $30 \%$, vibration amplitude is reduced.

(C) A small amount of alr bubbles (about 2\%) destabilizes cylinder vibration when $U_{r}$ is slightly smaller than the critical value. However, at $\alpha=30$ to $40 \%$, the vibration is suppressed somewhat.

(D) At high $\mathrm{U}_{\mathrm{r}}$, when the cylinder array is in a fluidelastic Instability region, alr bubbles have little effect on cylinder osc1llations.

These results were obtalned for tube rows. It is not certain the same conclusions can be made for other cylinder arrays.

For a cylinder array in two-phase flow below a certain critical flow velocity, oscillation amplitude increases with flow velocity. No major differences are observed in the lift and drag direction, although amplitudes may differ by a factor of two from one cylinder to another. The motion is exclted by turbulence and bubbles. An array contains many coupled modes. W1th turbulence and bubble excitations, there is no clear coherence or phase angle between different cylinders. These characteristics are similar to the single-phase flow. However, the cylinder response at low flow velocity is higher than in single-phase flow and, at high flow velocitles, the opposite is true. This trend is similar to that of a single cylinder in two-phase flow [Hara (1984)].

In subcritical vibration, the increase in cylinder response is generally related to a power of the flow velocity. In single-phase flow, the power is approximately equal to 2. However, in two-phase flow, the cylinder response is proportional to approximately the first power of the mass flux. Although Pettigrew and Gorman (1973) found the exponent to vary between 0.9 and 1.3 , Pettigrew et a1. (1985) show that the exponent decreases with $\alpha$, starting from 2 at $\alpha=0$, decreasing to 1 at $\alpha=0.20$, and to a little smaller than 1 for $\alpha>0.2$. The discrepancy between the single- and two-phase flow can probably attributed to the bubble excitations. It is possible that turbulence forces are less correlated at higher mass fluxes and thus reduce the vibration response. 


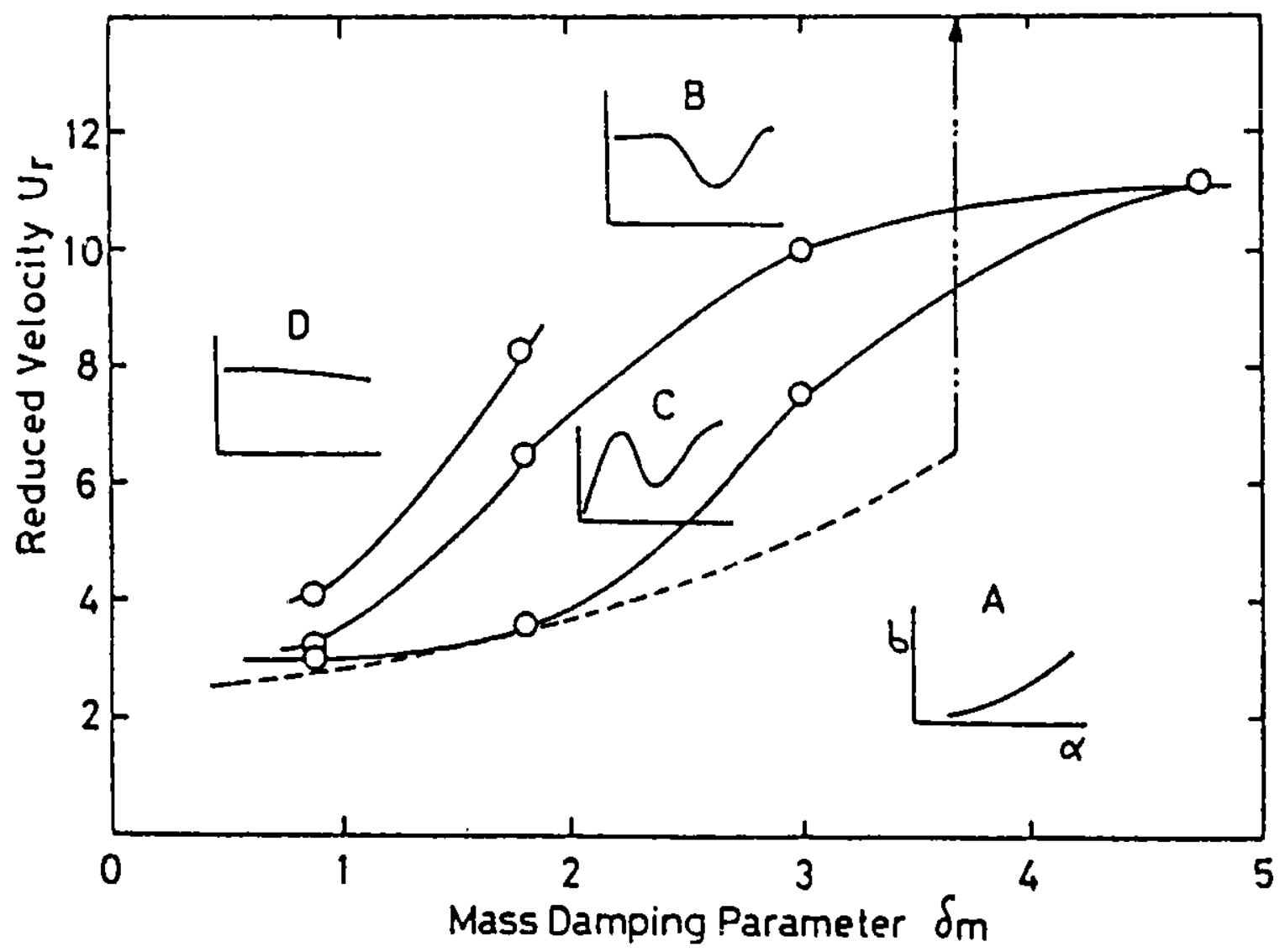

F1g. 8. Vibration characteristics $(\sigma=$ vibration amplitude, $\alpha=$ vold fraction) [from Hara (1987a), with permission] 
In two-phase flow, the vibration within an array and the vibration of different arrays are also not the same as in single-phase flow. For example, Pettigrew and Gorman (1973) found that in two-phase flow the upstream tubes vibrate most and for $a$ fixed $P / D$ and various classical tube layouts, the rotated square arrays vibrate most, the rotated trlangle and square arrays vibrate least, and the triangular arrays vibrate moderately. In addition, the preferred direction of motion is in the flow direction.

A cylinder array in two-phase flow will become unstable when the flow velocity is increased to a threshold value. Axisa et a1. (1984) found that there is a fairly clearly defined critical flow velocity below which cylinder displacement is increasing with flow velocity raised to a certain power. Above the critical flow velocfty the coherence and phase angle between varfous pairs of cylinders are well defined. In contrast, Pettigrew et al. (1985) found that the Instability thresholds are well defined at lower and higher $\alpha$ but less well defined at the intermediate values of vold fractions. In any case, both groups use the following stablilty criteria to correlate their data:

$$
\frac{U}{f D}=K\left(\frac{2 \pi \zeta m}{\rho D^{2}}\right)^{0.5}
$$

where $U$ and $p$ are given in Eqs. (4) and (5). Pettigrew et al. (1985) and Axisa et al. (1985), respectively, determined that $K$ 1s equal to 4.0 and 7.2

Hara (1987a) summarizes the published data for tube arrays as well as his own data in Fig. 9, where the broken lines are the theoretical results obtained by Chen and Jendrzejczyk (1983) in water flow. When the void fraction is small, the critical flow velocity increases with the void fraction. The mass-damping parameter also increases with the vold fraction owing to the reduction in two-phase flow density defined by the component $(1-\alpha) \rho_{\ell}$. For a relatively large mass-damping parameter $\left(\delta_{m}=3\right.$ to 5$)$, the critical flow velocity in two-phase flow is different from that for water flow.

In liquid flow, there exist two critical flow velocities: intrinsic critical flow velocity and exclted critical flow velocity. The former is larger than the latter by as much as 30\% [Chen and Jendrzejczyk (1987) and Hara (1987a)]. In two-phase flow, no such hysteresis 18 observed.

\section{Mathematical Hodels for Two-Phase Crossflow-Induced Vibration}

The analysis of an array of cylinders oscillating in two-phase flow has been performed based on the incorporation in the beam equation of some fluid effects [Pettigrew and Gorman (1973) and Axisa et a1. (1984)]. No analysis has been made for coupled modes of maltiple cylinders. A model based on coupled modes for single-phase flow is applied here to two-phase flow. 


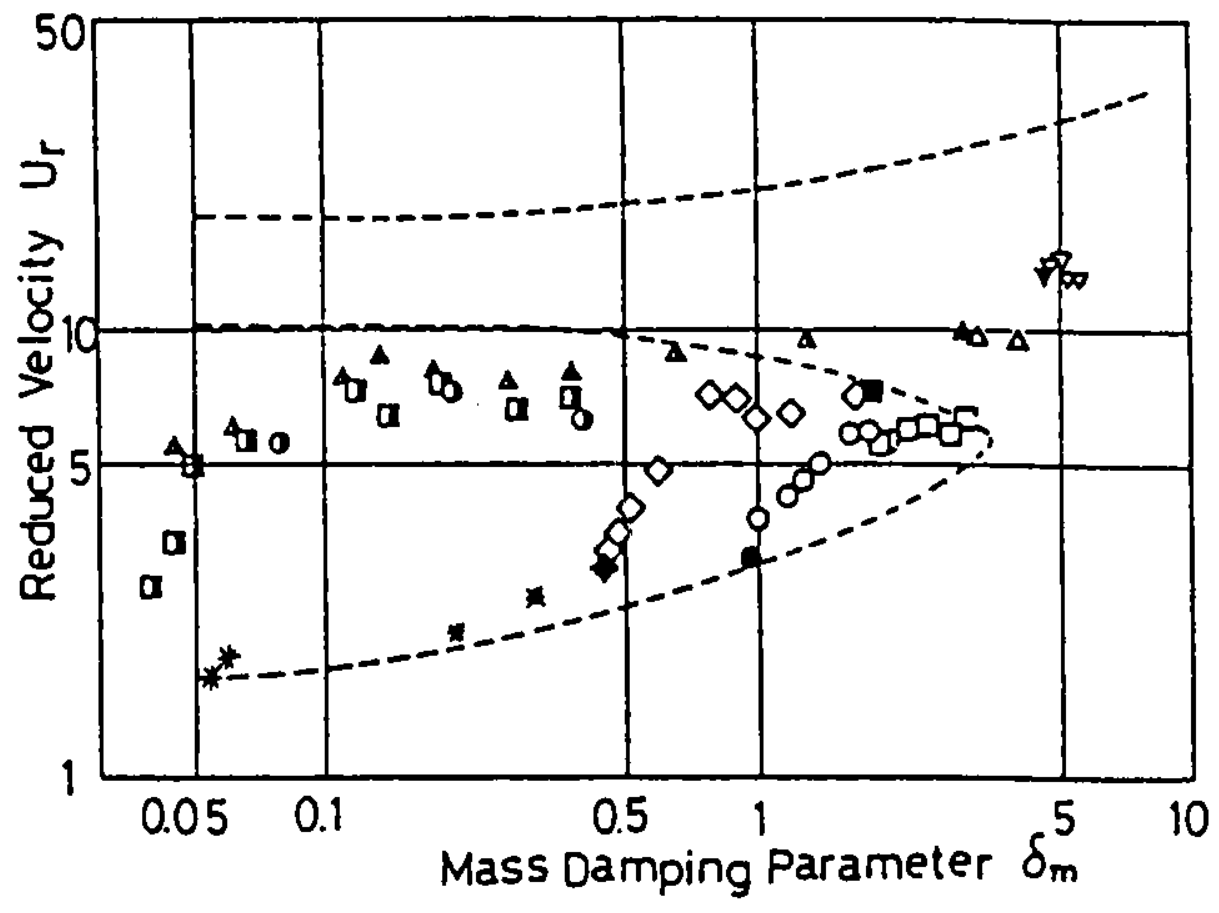

Fig. 9. Stability map: $\Delta$, : Pettigrew et al. (1985); O : Axisa et al. (1984); 0 : Yoshlkawa and Hara (1985); *: Tanaka and Takahara (1981); [from Hara (1987a), with permission] 
An array of $\mathrm{N}$ cylinders subjected to a crossflow is shown in Fig. 3 . The axes of the cylinders are parallel to the $z$ axis and flow is parallel to the $x$ axis. The subscript $j$ is used to denote variables associated with cylinder $j$. The variables assoclated with cylinder motion in the $x$ direction are flexural rigidity $E_{j}{ }_{j}$, cylinder mass per unit length $m_{j}$, the structural damping coefficlent $C_{s j}$, and displacement $u_{j}$. The equation of motion for cylinder $j$ in the $x$ direction is

$$
E_{j} I_{j} \frac{\partial^{4} u_{j}}{\partial z^{4}}+c_{s j} \frac{\partial u_{j}}{\partial t}+m_{j} \frac{\partial^{2} u_{j}}{\partial t^{2}}=g_{j}, \quad j=1,2,3, \ldots, N,
$$

where $g_{j}$ is the fluid force, including motlon-dependent fluid forces and fluid excitation forces. Simllarly, the equation of motion in the $y$ direction 18

$$
E_{j} I \frac{\partial^{4} v_{j}}{\partial z^{4}}+c_{8 j} \frac{\partial v_{j}}{\partial t}+m_{j} \frac{\partial^{2} v_{j}}{\partial t^{2}}=h_{j}, j=1,2,3, \ldots, N,
$$

where $v_{j}$ and $h_{j}$ are cylinder displacement and fluid-force component in the y direction, respectively.

The fluld force components $g_{j}$ and $h_{j}$ are given as follows [Chen (1987)]:

$$
\begin{aligned}
g_{j}=-\sum_{k=1}^{N}\left[\left(\bar{\alpha}_{j k} \frac{\partial^{2} u_{k}}{\partial t^{2}}+\bar{\alpha}_{j k}^{\prime} \frac{\partial u_{k}}{\partial t}+\bar{\alpha}_{j k}^{\prime} u_{k}\right)+\left(\bar{\sigma}_{j k} \frac{\partial^{2} v_{k}}{\partial t^{2}}\right.\right. \\
\left.\left.+\bar{\sigma}_{j k}^{\prime} \frac{\partial v_{k}}{\partial t}+\bar{\sigma}_{j k}^{\prime \prime} v_{k}\right)\right] \\
+\frac{1}{2} \rho U^{2} D C_{D j}+\frac{1}{2} \rho U^{2} D C_{D j}^{\prime} \sin \left(\Omega_{D j} t+\phi_{D j}\right)+g_{j}^{\prime},
\end{aligned}
$$

and

$$
\begin{aligned}
h_{j}=-\sum_{k=1}^{N}\left[\left(\bar{\tau}_{j k} \frac{\partial^{2} u_{k}}{\partial t^{2}}+\bar{\tau}_{j k}^{\prime} \frac{\partial u_{k}}{\partial t}+\bar{\tau}_{j k} u_{k}\right)+\left(\bar{B}_{j k} \frac{\partial^{2} v_{k}}{\partial t^{2}}\right.\right. \\
\left.\left.+\bar{B}_{j k}^{\prime} \frac{\partial v_{k}}{\partial t}+\bar{B}_{j k}^{\prime} v_{k}\right)\right] \\
+\frac{1}{2} \rho U^{2} D C_{L j}+\frac{1}{2} \rho U^{2} D C_{L j}^{\prime} \sin \left(\Omega_{L j} t+\phi_{L j}\right)+h_{j}^{\prime} .
\end{aligned}
$$


Note that $\bar{\alpha}_{i j}, \bar{\sigma}_{1 j}, \bar{\tau}_{1 j}$, and $\bar{\beta}_{1 j}$ are added mass matrices; $\bar{\alpha}_{i j}, \bar{\sigma}_{i j}, \bar{\tau}_{i j}$, and $\bar{B}_{i j}$ are fluid damping matrices; and $\bar{\alpha}_{1 j}, \bar{\sigma}_{1 j}, \bar{\tau}_{i j}$, and $\bar{B}_{i j}$ are fluid stiffness matrices. $C_{D j}\left(C_{L j}\right)$ is the steady drag (lift) coefficient, $C_{D j}^{\prime}\left(C_{L_{j}}\right)$ is the fluctuating drag (lift) coefficient, $\Omega_{D j}\left(\Omega_{L j}\right)$ is the circular frequency of periodic flow excitation in the drag (1ift) direction, $\phi_{D j}\left(\phi_{L j}\right)$ is the corresponding phase angle with respect to a particular fluid-force component, and $g_{j}\left(h_{j}\right)$ represents other fluctuating drag ( $11 \mathrm{ft}$ ) forces such as turbulent buffeting forces.

These equations are identical to those for single-phase flow. However, various fluid-force coefficients are different from those for single-phase flow.

Substituting Eqs. (26) and (27) into Eqs. (24) and (25) yields

$$
\begin{gathered}
E_{j} I_{j} \frac{\partial^{4} u_{j}}{\partial z^{4}}+C_{s j} \frac{\partial u_{j}}{\partial t}+m_{j} \frac{\partial^{2} u_{j}}{\partial t^{2}}+\sum_{k=1}^{N}\left(\bar{\alpha}_{j k} \frac{\partial^{2} u_{k}}{\partial t^{2}}+\bar{\sigma}_{j k} \frac{\partial^{2} v_{k}}{\partial t^{2}}\right) \\
+\sum_{k=1}^{N}\left(\bar{\alpha}_{j k}^{\prime} \frac{\partial u_{k}}{\partial t}+\bar{\sigma}_{j k}^{\prime} \frac{\partial v_{k}}{\partial t}\right)+\sum_{k=1}^{N}\left(\bar{\alpha}_{j k}^{\cdot *} u_{k}+\bar{\sigma}_{j k}^{*} v_{k}\right) \\
=\frac{1}{2} \rho U^{2} D C_{D j}+\frac{1}{2} \rho U^{2} D C_{D j}^{\prime} \sin \left(\Omega_{D j} t+\phi_{D j}\right)+g_{j}^{\prime}
\end{gathered}
$$

and

$$
\begin{gathered}
E_{j} I_{j} \frac{\partial^{4} v_{j}}{\partial z^{4}}+C_{s j} \frac{\partial v_{j}}{\partial t}+m_{j} \frac{\partial^{2} v_{j}}{\partial t^{2}}+\sum_{k=1}^{N}\left(\bar{\tau}_{j k} \frac{\partial^{2} u_{k}}{\partial t^{2}}+\bar{\beta}_{j k} \frac{\partial^{2} v_{k}}{\partial t^{2}}\right) \\
\quad+\sum_{k=1}^{N}\left(\bar{\tau}_{j k}^{\prime} \frac{\partial u_{k}}{\partial t}+\bar{B}_{j k} \frac{\partial v_{k}}{\partial t}\right)+\sum_{k=1}^{N}\left(\bar{\tau}_{j k} u_{k}+\bar{\partial}_{j k} v_{k}\right) \\
=\frac{1}{2} \rho U^{2} D C_{L j}+\frac{1}{2} \rho U^{2} D C_{L j}^{\prime} \sin \left(\Omega_{L j} t+\phi_{L j}\right)+h_{j}^{\prime} .
\end{gathered}
$$

Equations (28) and (29) are the equations of motion for cylinder $j$ in an array of cylinders subjected to crossflow. In a group of $N$ cylinders, there are $2 \mathrm{~N}$ equations of motion.

The response of an array of cylinders can be calculated falrly easily from Eqs. (28) and (29) If the vartous fluid forces in the equations of motion are known. It is stralghtforward to show that Eqs. (28) and (29) can be reduced to the standard form given in Eq. (9). A complete analysis of a cylinder array in crossflow requires knowledge of all the flutd forces. 
Unfortunately, at this time, complete information is not available for specific cylinder arrays. This suggests that, for practical applications, simplifications or assumptions must be made to solve the problem.

\section{Cylinders Inersed in Fluidized Beds}

So far discussions have been limited to two-phase flow consisting of two fluid components. Another important problem of two-phase crossflow-induced vibration is the fluidized bed. Heat is extracted from fluidized bed reactors by tube arrays immersed in the bed.

Whereas heat transfer in fluidized beds has received considerable attention, very little work has been reported on fiuid forces and assoclated tube vibration and wear. The limited number of undies reported in the open literature have all been published subsequent to 1980 [Kennedy et al. (1981), Turner and Irving (1982), Hosny and Grace (1983, 1984), and Grace and Hosny (1985)]. These investigations are useful because they provide insights into the characteristics of fluid forces acting on tube arrays in fluldized beds. Some of the essential characteristics determined from these studies can be suminarized as follows:

\section{Flow Regines}

In a fixed bed, up to the condition of inclplent fluidization, the tubes are subjected to an effective buoyancy force only. As the flow velocity increases to the bubbling regime, the tubes are subjected to a drag force in the downistream direction as the bubble approaches and to a force in the upstream direction as the bubble leaves the tube. Once the flow velocity is increased to the point where the flow is in the turbulent regime, the magnitude of the fluid force is reduced. The bubbling regime is of particular interest because the fluid force encountered has a maximum magnitude which is difficult to quantify.

\section{Tube Array vs. Single Tube}

Fluld forces depend on tube arrangement and spacing. Fluid forces acting on a tube array are smaller than those acting on the same tube in isolation. In general, the fluid force is largest on the upstream tube and smallest on the downstream tube. In addition, the peak frequency of the fluid forces for tubes in the middle of a tube array is higher because bubble splitting by the tube array results in a greater frequency of bubble-induced pulses. In a tube array, vertical components are also substantlally larger than the corresponding horlzontal components.

\section{Effects of Systen Parameters}

Tube Shape: Finned and unfinned tubes were tested by Grace and Hosny (1985). The rms fluld force acting on a flnned tube approaches the force acting on a bare tube of the same volume at low flow velocities and the force 
acting on a bare tube of diameter equal to the outer diameter at high flow velocities. Only one type of finned tube was tested. The effect of other types of fins is not known.

Bed Depth: The rms fluid forces increase with bed depth. This is attributed to the tendency of larger bubbles in the deeper beds to cause larger forces. In addition, in a shallower bed, the largest fluid force may occur in the middle of a tube array.

Particle Size and Density: At low flow velocities, particle size does not have any signiflcant effect on fluid forces, whereas at high flow velocities, particle size plays an important role. Fluid forces are also found to increase with particle density.

There are four basic excitation mechanisms for tube arrays subjected to single-phase crossflow: vortex shedding, fluidelastic Instability, turbulent buffeting, and acoustic resonance. In fluidized beds, in addition to these four excitation mechanisms, the excitation force attributed to the bubbles represerts an important mechanism. In the literature relating to forces on tubes in fluidized beds, the significance of the four basic mechanisins has not been exanined carefully.

(1) Vortex Shedding: It appears that no systematic investigations have been made to study the role of vortex shedding in fluidized beds or its effect on tube response. In flutdized beds, tube spacings are generally large. Consequently, at high flow velocitles, in particular in the dilute phase, vortex shedding could be an important excitation mechanism.

(2) Fluidelastic Instability: Because of the relatively large tube spacing in fluidized beds, the critical flow velocity at which large tube oscillations (Instability) occur is expected to be high. However, no analyses or experimental studies have been made to quantify the safety margin.

(3) Turbulent Buffeting: Random fluid forces in fluidized beds have been Identifled as an excitation mechanism. However, the determination of force magnitude, frequency spectra, and the nondimensional parameters required to quantify the characteristics of the turbulent buffeting forces remain Incomplete.

(4) Acoustic Resonance: Particles and tubes immersed in a fluid medium w111 reduce the effective speed of sound [Chen (1987)]. Therefore, the natural frequencies of acoustic modes in fluidized beds will be smaller than those for the corresponding single-phase flow without tubes. This effect will increase the chance of acoustic resonance and associated tube oscillations. In particular, in a large fluldized bed, acoustic resonance can be a potential problem.

From a review of the published data and a consideration of the potential excitation mechanisms, it may be concluded that, although the published data 
provide insights into the dynamic characteristics of the fluld forces acting on tube arrays in fluidized beds, a systematic study is lacking and urgently needed.

\section{AXIAL-FLOW-INDOCED VIBRATION}

Axial-flow-induced vibration problems can be divided into those attributable to Internal flow and those attributable to external flow. Twophase flow in pipes is a typical internal flow problem; nuclear fuel pins subjected to axial two-phase flow is a typical external flow problem. Both internal and external flow problems have been studied in the last 15 years.

\section{Internal Flow}

Pipes conveying a two-phase fluid have been studied by Hara (1973), Hara et al. (1974), Hara (1977), Hara (1980), Ylh and Griffith (1970), and Pettigrew and Paidoussis (1975). The dynamic responses considered include subcritical vibration, parametric resonance, and flutter.

The equation of motion for a plpe conveying a two-phase fluid is given by Hara (1977) as

$$
\begin{aligned}
& E I \frac{\partial^{4} u}{\partial z^{4}}+\left(m+M_{d}\right) \frac{\partial^{2} u}{\partial t^{2}}+2 M_{d} U \frac{\partial^{2} u}{\partial z \partial t}+M_{d} U^{2} \frac{\partial^{2} u}{\partial z^{2}} \\
& +\left(\frac{\partial M_{d}}{\partial t}+U \frac{\partial M}{\partial z}\right)\left(\frac{\partial u}{\partial t}+U \frac{\partial u}{\partial z}\right)=g(z, t)
\end{aligned}
$$

where the symbols are given in the nomenclature. Using the appropriate boundary conditions and the equation of motion, the internal flow problem is reduced to $\mathrm{Eq}$. (9).

Hara $(1973,1977)$ consldered the two-phase flow as periodic flow consisting of water slugi perlodically distributed in the pipe and moving at a constant speed. Using this flow model, Hara (1980) obtalned a system of Mathleu's equations from Eq. (30). Parametric resonance occurs if the ratio of the frequencies of water slugs and pipe natural frequency is $2,1,2 / 3$, $\ldots$ In addition, resonance occurs when the rat1o $181,1 / 2,1 / 3, \ldots$ When the ratio is equal to 1 , parametric excitation and resonance results in large oscillations. The theoretical result is verifled by experimental data. In general, vibration amplitude depends on the two-phase flow pattern and velocity; oscillation amplitude is largest for a piston flow. The excitation is attributed to periodic changes of the mass of the pipe/fluid system, which, in turn, results in periodic changes in system mass, centrifugal force, and the Coriolis force of liquid slugs in the pipe. 
Pettigrew and paidoussis (1975) performed tests on a cylinder immersed in an annulus two-phase flow. In the subcritical flow velocity range, the vibration response is falrly severe and broadbanded. The motion is excited by random turbulence associated with two-phase flow.

\section{External Flow}

Studies of cylinders submerged in two-phase flow are focused on nuclear fuel pins. Investigations have been reported for a single cylinder by Gorman (1971), Harris and Holland (1971), Harris and Ledwidge (1971), Harris and Holland (1973), Hara (1975a) and (1975b), Hara and Yamashita (1978), and Hara (1980); for multiple cylinders by Winsbury and Ledwidge (1973), Dallavalle et al. (1973), and Gorman (1975); and for simulated fuel bundles by Cedolin et a1. (1971), and Hayes (1982). A survey of this problem was reported by Shin (1978).

The equation of motion of a single cylinder in axial two-phase flow is still not well established. In the past, the Bernoulli-Euler beam equation of motion was used [Hara (1975a) and Gorman (1975)] and the fluld-force components associated with two-phase flow, including added mass, fluld damping, and fluid stiffness, were not accounted for consistently. Using the model for single-phase flow, Shin (1978) modifled the Chen and Wambsganss (1972) equation of motion for single-phase flow for application to two-phase flow. The modifled equation is as follows:

$$
\text { EI } \begin{aligned}
\frac{\partial^{4} u}{\partial z^{4}} & +\eta I \frac{\partial^{5} u}{\partial t \partial z^{4}}+m_{a}\left(\frac{\partial}{\partial t}+U \frac{\partial}{\partial z}\right)^{2} u \\
& -\left[\gamma T_{0}+\frac{1}{2} C_{T} \frac{m_{a} U^{2}}{D} G(z, t)+\frac{1}{2}(1-\gamma) C_{T}^{\prime} m_{a} U^{2}\right] \frac{\partial^{2} u}{\partial z^{2}} \\
& +\frac{1}{2} C_{N} \frac{m_{a} U C_{N}}{D}\left(\frac{\partial u}{\partial t}+U \frac{\partial u}{\partial z}\right)+C_{v} \frac{\partial u}{\partial t}+m \frac{\partial^{2} u}{\partial t^{2}}=g(z, t),
\end{aligned}
$$

where $n$ is the structural damping coefficlent, $C_{T}$ and $C_{N}$ are tangential and normal drag coefficients, respectively, $C_{T}$ is the drag coefficient at the free end, $T_{o}$ is the initial axial tension, and other symbols are 1isted in the nomenclature. In Eq. (31), $\gamma=0$ for a free-end, whereas for both ends fixed, $\gamma=1$. Equation (31) is an approximate equation of motion for a single cylinder in two-phase flow. Once the fluld-force coefficients are known it can be solved in a straightforward manner.

The characteristics of two-phase flows in the vicinity of PWR steam generator tube support plates were investigated in a qualitative nanner by Bates and Stewart (1979). The model test section consists of a $2 \times 2$ tube 
bundle fitted with prototypic support plates enclosed in a clear lucite flow housing. Figure 10 shows the flow patterns for various values of void fraction. Observations of both the in-operation test assembly and the highspeed motion plcture evidence reveal that very definite two-phase flow regimes could be distingulshed for different values of vold fraction:

$$
\begin{aligned}
& \alpha=0.1-0.3-\text { Low turbulence, bubbly flow, with uniform-size bubbles } \\
& \alpha=0.4-0.7-\text { More turbulent churning flow } \\
& \alpha=0.8-0.9-\text { More separated, osctllatory chugging or plug flow } \\
& \alpha=0.95 \quad \text { - Annular flow with the liquid phase concentrated on the } \\
& \text { wetted surfaces. }
\end{aligned}
$$

The driving force in two-phase flow originates from turbulence and bubble impacts. In addition, the time-varying virtual mass along the cylinder gives rise to the potential for parametric excitation. The phenomenon is the same as that for internal flow. Experiments and analysis of parametric excitation were performed by Hara (1980). Parametric resonance occurs when the ratio of the natural frequency of the cylinder to the void slug frequency is equal to $0.5,1$, and 1.5 , and resonance occurs when the ratio $1 \mathrm{~s}$ equal to $1,2,3$. The analysis can be based on Eq. (31). Hara simplified the analysis by neglecting the effect of drag forces. His experimental and analytical results agree reasonably well [Hara (1980)].

For subcritical vibration, it is important to characterize the flow fleld. Gorman (1971) studied the pressure fleld acting on the surface of a cylinder in an annulus. To eliminate the system noises, two pairs of diametrically opposite pressure transducers were used. The longitudinal and peripheral correlation, and power spectra of pressure fluctuations have been studied under different flow conditions. Figure 11 shows the longitudinal spatial correlation vs. transducer separation for two values of vold fraction. The correlation is found to be a damped cosinusoidal curve,

$$
A\left(z, z^{\prime}\right)=\exp \left(-\beta\left|z-z^{\prime}\right|\right) \cos \delta\left(z-z^{\prime}\right)
$$

Equation (32) is different from the exponential function for single-phase flow. Figure 12 shows the typical pertpheral spatial correlation. It is similar to a cosinusoldal distribution. Gorman (1971) suggested the following correlation:

$$
B\left(\theta, \theta^{\prime}\right)=\cos \left(\theta-\theta^{\prime}\right)-\lambda \sin 2\left|\theta-\theta^{\prime}\right|
$$



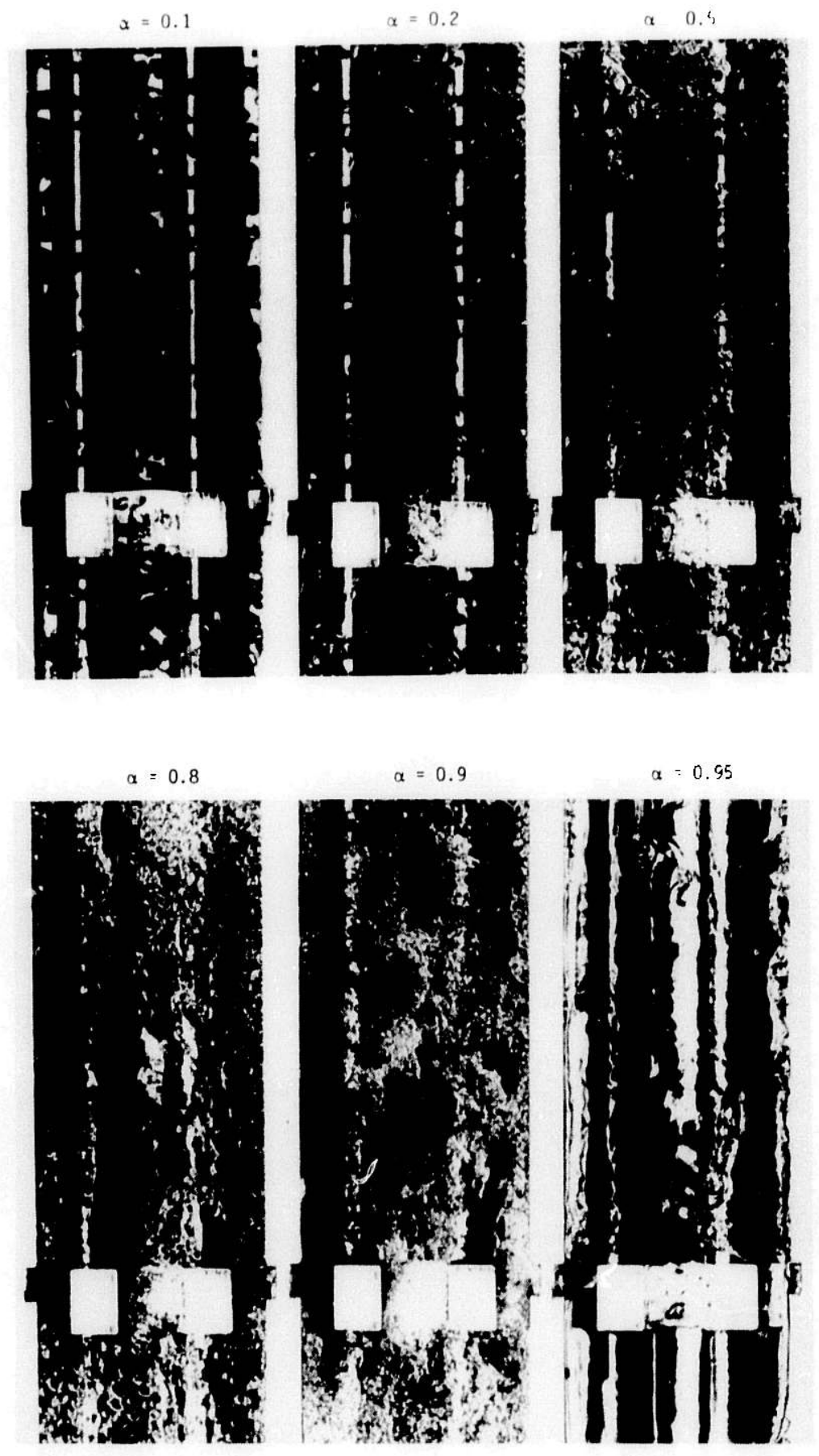

Fig. 10. Flow patterns in axial flow as a function of vold fraction [from Bates and Stewart (1979), with permission] 


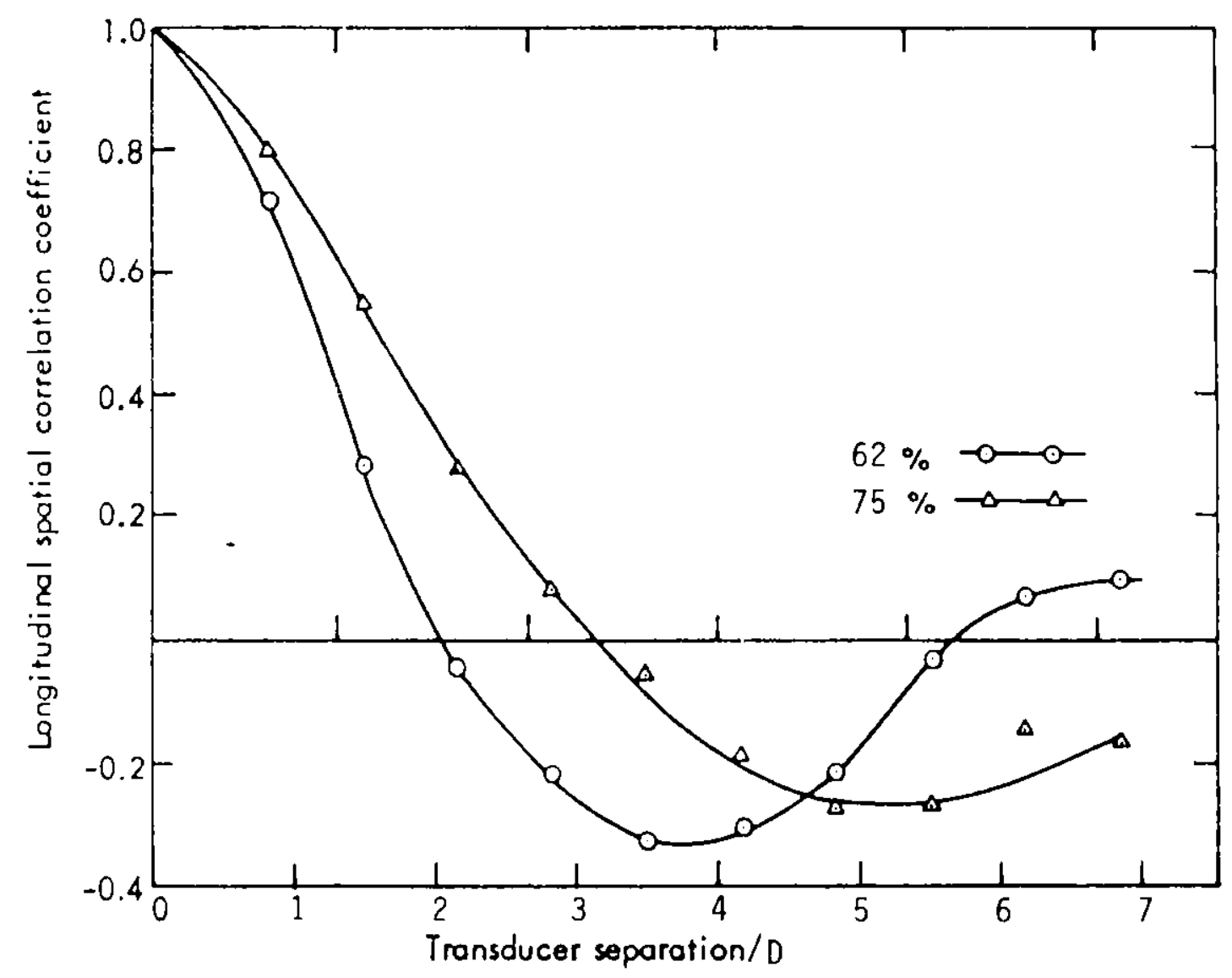

F1g. 11. Typical longitudinal spatial correlation of fluid pressure [from Gorman (1971), with permission] 


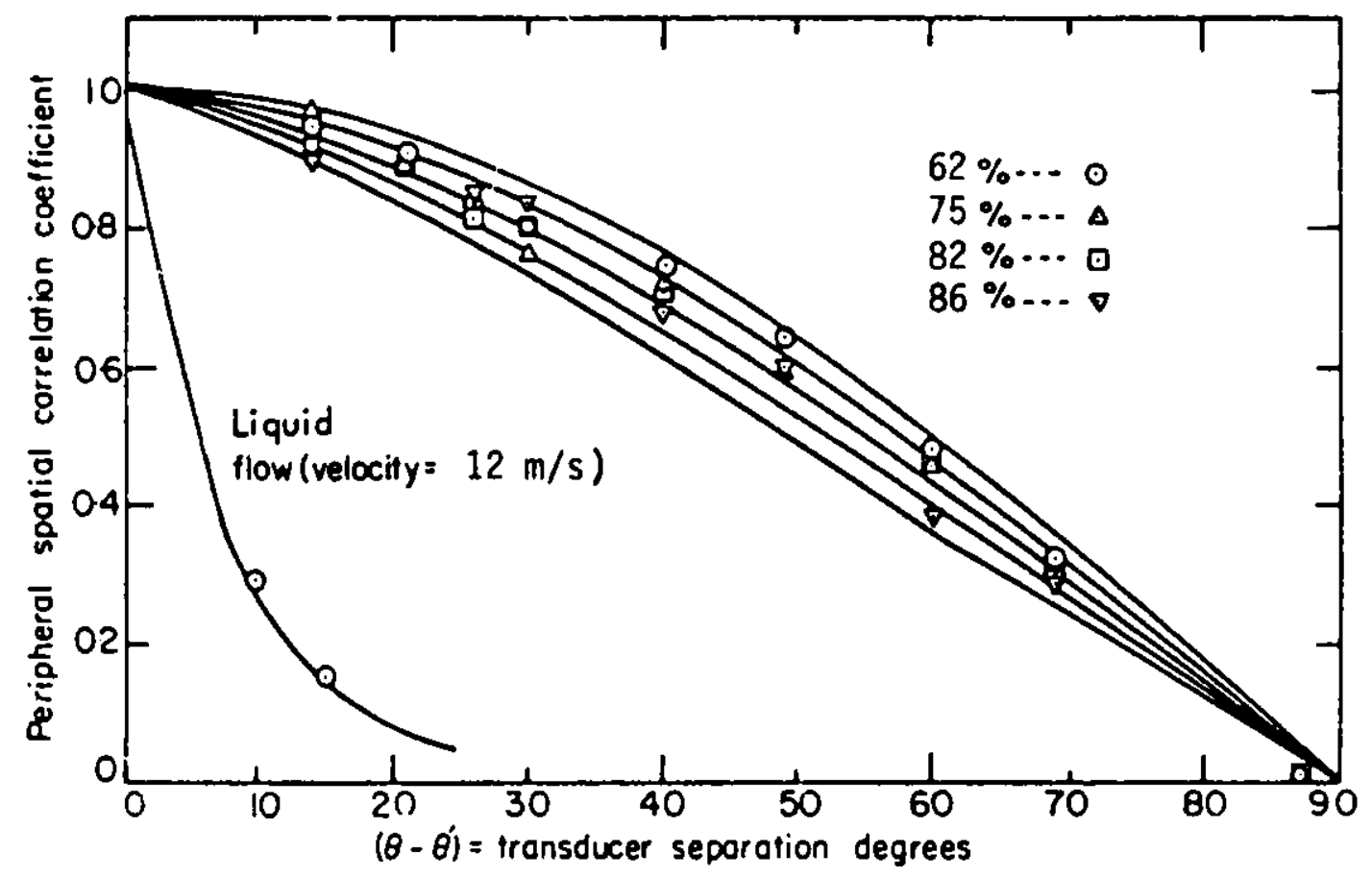

Fig. 12. Typical peripheral spatial correlation of fluid pressure [from Gorman (1971), w1th permission] 
where $\lambda$ may be selected to best fit the curve associated with each vold fraction.

Based on Gorman's study (1971), several conclusions can be made:

- The mathematical model for single-phase flow is applicable for twophase flow provided proper fluld parameters are used.

- There is good agreement between the shape of the measured displacement, the shape of the displacement predicted by the random vibration theory, and the measured boundary-layer pressure fluctuations. The vibration amplitude in two-phase flow is higher than that in single-phase flow because of higher peripheral spatial correlation of pressure fluctuations.

- Damping coefficlents associated with the first mode were found to be about four times as high as for liquid flow.

The effect of vold fraction on cylinder response is of particular Interest. Detalled studies have been performed by Harris and Holland (1973) and Winsbury and Ledwidge (1973). The cylinder response is found to be proportional to $\alpha^{n}(1-\alpha)$, mass flux, and other parameters. The values of $n$ are given by W1nsbury and Ledwidge (1973):

$$
\begin{array}{ll}
0.16<\alpha \leq 30, & \mathrm{n}=1.3 \\
0.30<\alpha<0.70, & \mathrm{n}=2.6 \\
0.70 \leq \alpha \leq 0.94, & \mathrm{n}=5.2 .
\end{array}
$$

Equation (34) is based on the1r own data and the results of others. For a given mass flux, the maximum response occurs for $0.80<\alpha<0.88$.

Hara (1980) studied the relation between vibration response and the Reynold's number, which 18 defined as $\left(1+Q_{a} / Q_{\ell}\right) D U_{\ell} / v_{\ell}$, where $Q_{A}$ and $Q_{\ell}$ are the flow rate of afr and water, respectively. A typlcal result is shown in Fig. 13. When Re 18 smaller than $6 \times 10^{4}$, vibration is small; when Re $>8.5 \times 10^{4}$, vibration 18 large.

The cylinder response for a simulated fuel rod in both a two-phase and bolling flow were measured by hayes (1982). The results show that the bolling tests and two-phase inlet tests resulted in higher vibration than that obtalned in singlemphase flow. For a constant mass flux, the fuel rod vibration peaks at a particular vold fraction in both, bolling and adiabatic, two-phase flows. 


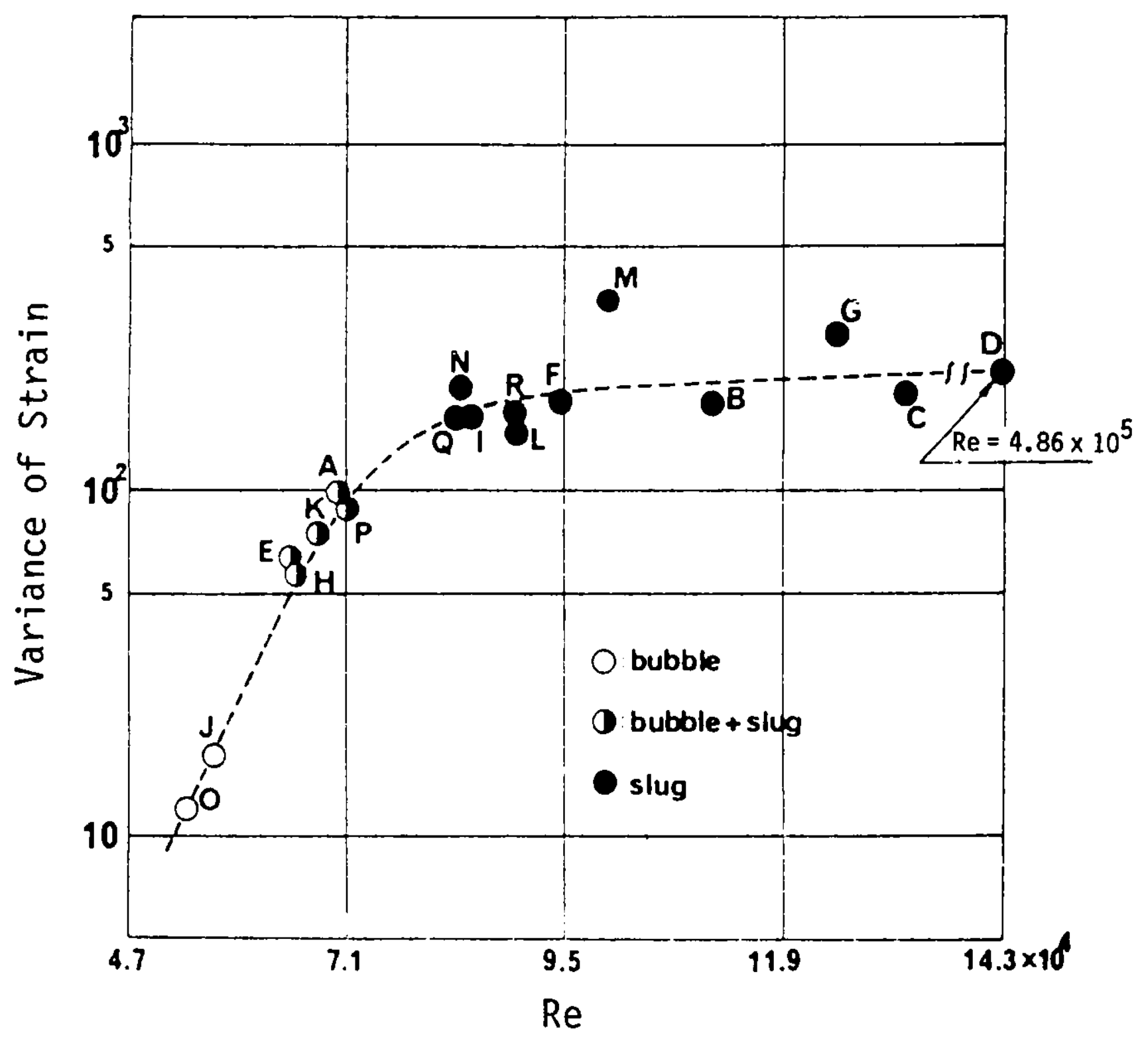

Fig. 13. Variance of vibration strain and two-phase flow Reynolds number Re [from Hara (1980), with permission] 


\section{v. CLOS ING REMARKS}

The effect of two-phase flow is much more complicated than that of single-phase flow. This is attributed to the fluctuations of flow rate, density and pressure gradients, as well as oscillations due to compressibility of the fluid. The passage of bubbles is accompanied by microhydratic impacts, which produce fluctuation forces in two-phase flow. Therefore, in addition to the pressure fluctuations encountered in single-phase flow, the microhydraulic impacts associated with two-phase flow are very important.

The mechanisms of two-phase flow-1nduced vibration include subcritical vibration excited by turbulence and bubble 1mpacts, parametric resonance associated with the periodic varlation of mass flux, vortex-lnduced vibration for small vold fractions, and large amplitude oscillation of fluidelastic instability. Reported studies of these phenomena for axial- and crossflow Indicate that progress has been made. However, investigations that are much more systematic are needed. Several toplcal areas are important:

- Flow fleld: Flow velocity distribution in heat transfer equipment, distribution of bubbles, mathematical characterization of flow patterns and effect of system parameters on flow fleld.

- Fluid Excltation Forces: Power spectral density of fluid excltation forces, axtal and peripheral correlation of fluid pressure fluctuations, and effect of vold fraction on fluid excitation forces.

- Motion-Dependent Fluid Forces: Added mass, fluld damping, and fluld stiffness as a function of vold fraction and flow rate for different cylinder arrays as well as different oscillation frequencies.

- Cylinder Response: Mathematical models that incorporate all fluid effects, simplified equations for different excitation mechanisms, and response as a function of system parameters.

- Design Guldes: Relationship between two-component (e.g., air-water) two-phase flow and single-component (e.g., steam-water) two-phase flow, design guldes for predicting cylinder response, acceptance criterla, and design modification techniques.

All of the above toplcs are very important and must be studied to resolve the issues of two-phase flow-induced vibration and to provide the basis for the development of prediction methods and design guides. Argonne National Laboratory is planning a comprehensive research program to look into this subject. A two-phase air-water loop is being designed. Experiments are expected to begin in FY 1988. A series of tests will be performed to study fluld excltation force, cylinder response, and motion-dependent fluid forces. 


\section{ACKNOULEDGERTS}

This work was sponsored by the U. S. Department of Energy (DOE), Office of Energy Utillzation Research, under the Energy Conversion and Utilization Technologies (ECUT) Program. The continuing encouragement and support of

M. E. Gunn, J. J. Eberhardt, and W. H. Thielbahr of US/DOE are appreciated. 


\section{REFBRBNCES}

Axisa, F., et a1. 1984. Vibration of Tube Bundles Subjected to Air-Water and Steam-Water Cross Flow: Preliminary Results on Fluldelastic Instabiltty. ASME Symposium on Flow-Induced Vibration, Vol. 2, pp. 269-284.

Axisa, F., et al. 1985. Vibration of Tube Bundles Subjected to Steam-Water Cross Flow: A Comparative Study of Square and Trtangular Pitch Arrays. Trans. 8th Int. Conf. on Structural Mechanics in Reactor Technology. Paper No. Bl/2.

Axisa, F., et al. 1986. Flow-Induced Vibration of Steam Generator Tubes. EPRI NP-4559, Electric Power Research Institute, Palo Alto, CA.

Bates, J. M., and Stewart, C. W. 1979. Experimental Study of Single- and Two-Phase Flow Flelds Around PWR Steam Generator Tube Support Plates. EPRI NP-1142, Research Profect 1121, Electric Power Research Institute, Palo Alto, CA.

Carlucci, L. N. 1980. Damping and Hydrodynamic Mass of a Cylinder in S1mulated Two-Phase Flow. J. Mech. Des. 102, 597-602.

Carluccl, L. N., and Brown, J. D. 1983. Experimental Studies of Dainpling and Hydrodynamic Mass of a Cylinder in Confined Two-Phase Flow. ASME Trans.; J. Vib., Acoust., Stress and Rellability in Des. 105, 83-89.

Cedolin, L., Hassid, A., Rossint, T., and Sobleri, R. 1971. Vibrations Induced by the Two-Phase Coolant Flow in the Power Channels of a Pressure Tube Type Reactor. Trans. 1st Int. Conf. on Structural Mechanics in Reactor Technology. Paper No. E4/5.

Chen, S. S. 1987. Flow-Induced V1bration of Circular Cylindrical Structures. Hemisphere Publishing Co., New York.

Chen, S. S., and Chung, H. 1976. Design Gutde for Calculating Hydrodynamic Mass, Part I: Circular Cylindrical Structures. ANL-CT-76-45, Argonne National Laboratory, Argonne, IL.

Chen, S. S., and Jendrzejczyk, J. A. 1983. Stablltty of Tube Arrays in Crossflow. Nucl. Eng. Des. 75(3), 351-374.

Chen, S. S., and Jendrzejczyk, J. A. 1986. Fluid Excitation Forces Acting on a Tube Array. In Measuring and Metering of Unsteady Flows, ASME Publication, FED-Vol. 40, pp. 45-55.

Chen, S. S., and Jendrzejczyk, J. A. 1987. Characterlstics of Fluidelastic Instability of Tube Rows in Crossflow. Presented at the Int. Conf. on Flow Induced Vibration, Bowness-on-W1ndermere, England, May 12-14. Paper No. B3.

Chen, S. S., and Wambsgans8, M. W. 1972. Parallel-Flow-Induced Vibraticn of Fuel Rods. Nucl. Eng. Des. 18, 253-278.

Chen, S. S., Wambsganss, M. W., and Jendrzejczyk, J. A. 1976. Added Mass and Damping of a Vibrating Rod in Confined Viscous Fluids. ASME Trans.; J. Appl. Mech. 43, 325-329. 
Collier, J. G. 1981. Convectlve Bolling and Condensation, 2nd Ed. McGrawH111 Book Company (U.K.) Ltd., New York.

Dallavalle, F., Rossint, T., and Vanolf, G. 1973. Vibrations Induced by a Two-Phase Parallel Flow to a Rod Bundle: Preliminary Experiments on the Surface Tenston and Gas Density Effect. Proc. Int. Symp. Vibration Problems in Industry 5 , No. 525, Keswick, England.

Gorman, D. J. 1971. An Analytical and Experimental Investigation of the Vibration of Cylindrical Reactor Fuel Elements in Two-Phase Parallel Flow. Nucl. Sct. and Eng. 44, 277-290.

Gorman, D. J. 1975. Experimental and Analytical Study of Liquid and TwoPhase Flow Induced Vibration in Reactor Fuel Bundles. ASME Publications, Paper No. 75-PVP-2.

Goyder, H. G. D. 1987. Two-Phase Buffeting of Heat Exchanger Tubes. Presented at the Int. Conf. on Flow Induced Vibration, Bowness-on-Windermere, England, May 12-14. Paper No. E2

Grace, J. R., and Hosny, N. 1985. Forces on Hortzontal Tubes in Gas Fluidized Beds. Chem. Eng. Res. Des. 63, 191-198.

Hara, F. 1973. A Theory on the Two-Phase Flow Induced Vibrations in Piplng Systems. Trans. 2nd Int. Conf. on Structural Mechantcs in Reactor Technology. Paper No. F5/15.

Hara, F. 1975a. A Theory on the Vibrations of a Fuel Pin Model 1n Parallel Two-Phase Flow. Trans. 3rd Int. Conf. on Structural Mechanics In Reactor Technology. Paper No. D2/4.

Hara, F. 1975b. Experilnental Study of the Vibrations of a Fuel Pin Model in Parallel Two-Phase Flow. Trans. 3rd Int. Conf. on Structural Mechanics in Reactor Technology. Paper No. D2/3.

Hara, F. 1977. Two-Phase-Flow-Induced Vibrations in a Horizontal Piping system. Bull. JSME 20, 419-427.

Hara, F. 1980. Two-Phase Flow Induced Parametrlc Vibrations in Structural Systems - Pipes and Nuclear Fuel Pins. Rep. Inst. Ind. Sc1., Univ. Tokyo 28, Series 183, $1-43$.

Hara, F. 1982. Two-Phase Cross-Flow-Induced Forces Acting on a Circular Cylinder. ASME Publication, PVP-Vol, 63, pp. 9-17.

Hara, F. 1984. Air-Bubble Effects on Vortex-Induced Vibrations of a Circular Cylinder. ASME Symposium on Flow-Induced Vibrations, Vol. 1, pp. 103-113.

Hara, F. 1987a. Vibration of a Single Row of vircular Cylinders Subjected to Two-Phase Bubble Cross-Flow. Presented at the Int. Conf. on Flow Induced Vibration, Bowness-on-W1ndermere, England, May 12-14. Paper No. El.

Hara, F., 1987b. Vibrations of Circular Cylindrical Structures Subjected to Two-Phase Cross Flows. JSME Int. J. 30(263), 711-722. 
Hara, F., and Kohgo, 0. 1982. Added Mass and Damping of a Vibrating Rod in a Two-Phase Air-Water Mixed Fluid. ASME Publication, PVP-Vol. 63, pp. 1-8.

Hara, F., and Kohgo, 0. 1986. Numerlcal Approach to Added Mass and Damping of a Vibrating Circular Cylinder in a Two-Phase Bubble Fluid. In Proc. Int. Conf. on Computational Mechantes, 2 , pp. VII-255.

Hara, F., Shigeta, T., and Shlbata, H. 1974. Two-Phase Flow by Induced Random Vibrations. In Flow-Induced Structural Vibrations, E. Naudascher, Ed., pp. 691-700, Springer-Verlag, Berlin.

Hara, F., and Yamashita, T. 1978. Parallel Two-Phase-Flow-Induced Vibrations in Fuel Pin Model. J. Nucl. Sci. Technol. 15, 346-354.

Harris, R. W., and Holland, P. G. 1971. Response of a Cylindrical Cantilever to Axial Air Water Flow. Trans. 1st Int. Conf. on Structural Mechanics Lı Reactor Technology. Paper No. E3/6.

Harris, R. W., and Holland, P. G. 1973. An Experimental Study on FlowInduced Vibration of a Cantllever in Axial Air-Water Flow. Trans. 2nd Int. Conf. on Structural Mechantcs in Reactor Technology. Paper No. D3/4.

Harris, R. W., and Ledwidge, T. J. 1971. The Relationship Between the Coherence Length of a Two Phase Mixture and the Response of a Cylindrical Cantilever. Fourth Australasian Conf. on Hydraulics and Fluid mechanics, Monash Univ., Melbourne, Australia, Nov. 29-Dec. 3.

Hayes, C. G. 1982. Fuel Rod Vibration in Two-Phase Flow. GEAP-22077, General Electric, San Jose, CA.

Heflker, W. J., and Vincent, R. Q. 1980. Vibration in Nuclear Heat Exchangers Due to Llquid and Two-Phase Flow. Presented at the Century 2 Nuclear Englneering Conference, San Francisco, CA, Aug. 19-21. ASME Paper No. $80-\mathrm{C} 2 / \mathrm{NE}-4$.

Hosny, N., and Grace, J. R. 1983. Forces on a Tube Immersed with1n a Fluidized Bed. In Fluidization, D. Kunl1 and R. Toe1, Eds., pp. 111-120, Engineering Foundation, New York.

Hosny, N., and Grace, J. R. 1984. Translent Forces on Tubes within an Array In a Fluidized Bed. ALChE J. 30, 974-976.

Kennedy, T. C., Konovan, J. E., and Titgas, A. 1981. Forces on Immersed Tubes in Flutdized Beds. AIChE J. 27, 351-357.

Nakamura, T., et al. 1982. An Experimental Study on Exciting Forces by TwoPhase Cross-Flow. ASME Publication, PVP-Vo1. 63, pp. 19-29.

Nakamura, T., and Fujita, K. 1987. A Study on Impact Vibration of Loosely Held Tube by Cross Flow. Presented at the Int. Conf. on Flow Induced Vibration, Bowness-on-W1ndermere, England, May 12-14. Paper No. Kl. 
Pettlgrew, M. J., and Gorman, D. J. 1973. Experimental Studies on FlowInduced Vibration to Support Steam Generator Design; Part III: Vibration of Sma11 Tube Bundles in Liquid and Two-Phase Cross-Flow. Presented at the Int. Symp. on Vibration Problems in Industry, Keswick, England, April 10-14.

Pettigrew, M. J., and Gorman, D. J. 1978. Vibration of Heat Exchange Components in Liquid and Two-Phase Cross-Flow. Int. Conf. on Vibration in Nuclear Plant, Keswick, England, May 9-12.

Pettigrew, M. J., and Paidoussis, M. P. 1975. Dynamics and Stability of Flexible Cylinders Subjected to Liquid and Two-Phase Axial Flow in Confined Annul1. Presented at the 3rd Int. Conf. on Structural Mechanics in Reactor Technology, London, U.K., Sept. 1-5.

Pettigrew, M. J., Tromp, J. H., and Mastorakos, J. 1985. Vibration of Tube Bundles Subjected to Two-Phase Cross-Flow. J. Pressure Vessel Technol. 107, 335-343.

Remy, F. N. 1982. Flow Induced Vibration of Tube Bundles in Two Phase Cross Flow. Third Keswick International Conference, English Lakes, U.K., May 11-14.

Schumann, V. 1981. Virtual Density and Speed of Sound in a Fluid-Solid Mixture with Periodic Structures. Int. J. Multiphase Flow 7, 619-633.

Shin, Y. W. 1978. Two-Phase Flow-Induced Vibrations of Rods in Parallel Flow: A State-of-the-Art Review. GEAP-24148; ANL-CT-78-18, Argonne National Laboratory, Argonne, IL.

Skop, R. A., Ramberg, S. E., and Fever, K. M. 1976. Added Mass and Damping Forces on Circular Cylinders. ASME Publication, Paper No. 76-PET-3.

Tanaka, H., and Takahara, S. 1981. Fluid Elastic Vibration of Tube Array in Cross-Flow. J. Sound Vib. 77, 19-37.

Taylor, C. E., Pettlgrew, M. J., Axisa, F., and Villard, B. 1986. Experimental Determination of Single and Two-Phase Cross Flow-Induced Forces on Tube Rows. In Flow-Induced Vibration - 1986, ASME Publication, PVP-Vo1. 104, pp. 31-39.

Turner, M. J., and Irving, D. 1982. Forces on Tubes Immersed in a Fluidized Bed. In Proc. of the 7 th Int. Conf. on Fluidized Bed Combustion, Vol. 2, pp. 831-839.

Winsbury, G. J., and Ledwidge, T. J. 1973. An Experimental Study of Vibration of a Cluster of Flexible Hollow Cylinders in Axial Air-Water Flow. Trans. 2nd Int. Conf. on Structural Mechanics in Reactor Technology. Paper No. D3/5.

Y1h, T. S., and Griffith, P. 1970. Unsteady Momentum Fluxes in Two-Phase Flow and the Vibration of Nuclear System Components. Proc. of the Conf. on Flow-Induced Vibrations in Reactor System Components, Argonne National Laboratory, Argonne, IL, May 14-15.

Yoshikawa, N., and Hara, F. 1985. Vibrations of a Single Row of Circular Cylinders Subjected to Two-Phase Cross-Flow. (In Japanese). Trans. JSME 51, pp. 2487. 
Distribution for ANL-87-28

Interna1:

H. Drucker

R. W. Weeks

C. A. Kot

M. W. Wambsganss

R. E. Holtz

W. W. Schertz

S. S. Chen (15)

H. H. Chung

H. Halle

J. A. Jendrzejczyk
T. M. Mulcahy

W. T. Sha

Y. W. Shin

K. E. Kasza

A. Thomas

E. M. Stefansk1

ANL Patent Dept.

ANL Contract FIle

ANL Libraries

TIS Files (5)

\section{External:}

DOE-TIC for distribution per UC-95f (168)

Manager, Chicago Operations Office, DOE

Di rector, Technology Management Div., DOE-CH

D. L. Bray, DOE-CH

A. L. Taboas, DOE-CH

C. B. Alcock, Unfversity of Toronto, Toronto, Ontario, Canada

P. G. Shewmon, Oh10 State University, Columbus, OH

H. L. Anderson, Ontario Hydro

M. K. Au-Yang, B\&W

K. J. Be11, Oklahoma State Univ.

A. E. Bergles, Iowa State UnIv.

M. D. Bernstein, FWEC

R. D. Blevins, Rohr Industries

J. C. Blomgren, Commonwealth Edison

G. N. Bogel, Dow Chemical

G. J. Bohm, Westinghouse PWR Systems

G. Borushko, Westfleld, NJ

J. J. Brogan, DOE/Conservation

G. M. Cameron, Chemetics

C. A. Chandley, TVA

S. Chandra, Northeast Utilities

P. Y. Chen, NRC

J. M. Chenoweth, HTRI

M. A. Chionchio, Southwestern Eng.

D. ChIsholm, HTRI

H. J. Connors, Westinghouse R\&D

R. J. Croke, Lummus Co.

J. L. Dixon, Southern Heat Exch. Corp.

J. J. Eberhardt, DOE/Conservation

F. L. Eisinger, FWEC

R. L. Eshleman, Vibration Institute

D. F. Fijas, Amerlcan Standard

R. J. Fritz, GE/KAPL

N. R. Gainsboro, Southwestern Eng.

C. C. Gentry, Ph1ll1ps Petroleum Company

R. Ghat tas, Quadrex

J. S. Gosnell, Braldwood Nucl. Power Station 
S. Green, EPRI

K. G. Grinnell, Graham Mfg. Co.

M. E. Gunn, DOE/Conservation

R. T. Hartlen, Ontario Hydro

M. Hartzmann, NRC/NRR

K. H. Haslinger, $C E$

G. Hausenbauer, Struther-Wells

T. G. Haynes, Duke Power

T. D. Haze11, Foster Wheeler, England

W. J. Heilker, CE

L. W. Heilman, Nooter Corp.

T. G. Heilmann, Chemetics

D. M. Himmelblau, U. Texas at Austin

N. Hi rota, EPRI

R. Hutchensen, Battelle, PNL

B. Johnson, Pacific Northwest

D. L. Johnson, M. W. Kellogg Company

A. F. Jones, du Pont

S. P. Kalra, EPRI

A. V. Karvelis, Borg-Warner

R. A. Kenny, CE

E. Kiss, General Electric Co.

J. H. Kisse1, American Standard

F. Kreith, SERI

W. Lampert, Vapor Corporation

P. A. Larsen, Amoco Oil Co.

M. LeFevre, Research Cottrell

S. F. Lindsey, Duke Power

B. T. Lubin, CE

P. J. Marto, U.S. Naval Postgraduate Schoo1

A. J. Meehan, Word Industries

P. M. Moretti, Oklahoma State Univ.

A. Morris, TVA

T. J. Muldoon, Heat Transfer Specialists

K. Nelson, Manning \& Lewis Eng.

E. H. Novendstern, Westinghouse Électric Corp.

S. Oppegaard, Commonwealth Edison

R. Penney, A. E. Staley Company

A. Poureshmenantalemy, Dravo Engrs.

S. Proctor, Monsanto Company

T. J. Rabas, Westinghouse Electric Corp.

J. Rajan, NRC

J. F. Reiss, Commonwealth Edison

S. Richlen, DOE/OIP

R. B. Ritter, Fluor Engrs \& Constructors

D. Rockwell, Lehigh University

E. Rodriguez, General Dynamics
T. M. Rudy, Exxon R\&D Labs

J. B. Sandifer, B\&W/ARC

S. D. Savkar, GE/CRD

M. Sax, Westinghouse Bettis

W. Schnetder, B\&W/Canada

J. E. Schroeder, Nooter Corporation

R. K. Shah, Harrison Radiator

W. Simmons, General Dynamics

J. C. Simonis, Southwest Res. Inst.

L. L. Simpson, Union Carbide

K. P. Singh, Holtec International

$\mathrm{N}$. R. Singleton, Westinghouse Electric Corp.

D. Steininger, EPRI

A. L. Sudduth, Duke Power Co.

J. Taborek, Austin, TX

K. K. Tam, Amoco Oil Co.

W. H. Thielbahr, DOE/ID

M. R. Torres, General Electric

S. N. Tower, Westinghouse Monroeville

J. Tsou, EPRI

M. E. Underwood, Badger Co.

G. H. Weidenhamer, NRC/RES

J. Yampolsky, GA Technologies, Inc.

E. Young, University of Michigan

E. A. Zanoni, Westinghouse Bettis 